\title{
Part(y) of Speech: Partisan Divides in Stylistic Framing
}

\author{
Ryan B McMahon*
}

November 10, 2018

\begin{abstract}
Research investigating the use of framing in political texts shows that politicians frame issues and themselves differentially based on social identities and other, external, factors. However, this literature focuses almost exclusively on what words are said (i.e., the content), with minimal attention being paid to how they are said (i.e., the style). This pre-registered study uses text annotation methods and an original collection of senate press releases to demonstrate that politicians also engage in stylistic framing. Like content frames, the use of style frames differs by partisanship in a manner consistent with party principles. Republican press releases are more likely to focus on the past and draw attention to individuals. Releases from Democratic senators, on the other hand, are more likely to discuss the future and focus on groups.
\end{abstract}

Framing is an integral aspect of politics writ large (Alexander 2008; Grimmer 2013b; Lakoff 2010; Monroe, Colaresi and Quinn 2008). This well developed literature has demonstrated that media frames can affect people's tendency to view poverty being caused by individuals or society (Iyengar, Peters and Kinder 1982; Iyengar 1990), tolerance for the Ku Klux Klan (Nelson, Clawson and Oxley 1997), the amount of attention politicians devote to an issue (Walgrave et al. 2017), and that framing can influence specific and diffuse support for the Supreme Court (Nicholson and Howard 2003).

Though historically difficult to measure (e.g., Fenno 1978; Mayhew 1974), the explosion of machinereadable text and accompanying analytics have provided researchers with an opportunity to investigate political framing in a quantitative manner, on an unprecedented scale. Scholars have taken well to this: examining topics ranging from issue framing by legislators (Monroe, Colaresi and Quinn 2008; Jensen et al. 2012) and media outlets (e.g., Gentzkow and Shapiro 2010) to how those same entities allocate attention to different issues (Baumgartner, De Boef and Boydstun 2008; Card et al. 2015; Grimmer 2013b). Furthermore, they have developed a variety of new methodological tools to advance these investigations (e.g., Fong and Grimmer 2016; Grimmer 2010; Laver, Benoit and Garry 2003; Monroe, Colaresi and Quinn 2008; Roberts et al. 2013; Slapin and Proksch 2008).

Despite the burgeoning interest in political text and framing, researchers have focused almost exclusively on what words are said (i.e., the content), with minimal attention paid to how they are said (i.e., the style)

\footnotetext{
${ }^{*}$ Ryan is currently a data scientist at Verisk Maplecroft and this piece is a chapter from his dissertation. He can be reached at ryan.mcmahon@maplecroft.com. A big thanks to my committee Suzanna Linn, Michael Nelson, Zita Oravecz, and Burt Monroe for all of their helpful feedback. Additionally, thank you to Amber Boydstun and Michael Kenwick, both of whom provided useful insight. The author, and the author alone, is responsible for any errors or inaccuracies contained herein.
} 
- though see Fausey and Matlock (2011). ${ }^{1,2}$ Presumably, if asked to think of two opposing frames on the issue of gun control in America, many people would generate examples related to constitutional rights and public safety. These differing perspectives are based on content - focusing on a particular aspect of an issue.

While linguistic content has been the primary focus of research on the topic, it alone cannot describe all aspects of political framing. As such another class of interesting questions have been left unanswered. Did the author center their discussion on what has been done, what is being done, or what will be done? Did they focus on individuals or groups? Do they talk about "our jobs" or "their jobs"? Questions of this nature concern linguistic style rather than content (Pennebaker, 2013). The placement of such minimal import on the study of style has left scholars with little knowledge about how, when, by whom, and to what end it is used in political framing. The investigation of this topic is important for a number of reasons. First and foremost, given the abundance of evidence from content studies (e.g., Chong and Druckman 2007), it is not unreasonable to suspect that style frames can also influence the opinions individuals express about issues and other people (see Baldwin and Lammers 2016; Lammers and Baldwin 2018). Studying stylistic frames can also add nuance to our understanding of content framing. What aspect of an issue a presenter decides to emphasize is important, but how she does so and how that augments the content are too. Finally, stylistic frames are not only important for understanding particular issues, but they can also be understood to apply across issues. ${ }^{3}$

In this paper I build on earlier, content-focused studies to investigate partisan differences in stylistic framing, thereby addressing the lack of attention on linguistic style in existing research. Linking literatures from political science, psychology, and linguistics, I put forth novel predictions about the relationship between partisanship and the use of stylistic frames. Specifically, I argue that the Democratic and Republican parties' divergent perspectives on novelty and social responsibility should be apparent in their use of temporal and subject-scope frames. These stylistic frames are manifest in the grammatical features of verb tense and (pro)noun number (i.e., plural vs. singular), which provide an intuitive operationalization.

Using newly collected Senate press releases from the 114th Congress (2015-16) and text annotation methods from the fields of natural language processing (NLP) and computational linguistics (CL), I find support for my pre-registered expectations about the existence and direction of differences in the grammatical tendencies of Republicans and Democrats. ${ }^{4}$ While Republican senators are more likely to use past tense

${ }^{1}$ This is not meant as a reference to equivalency-based frames, where logically equivalent (typically numerical) statements are judged differently depending on how they are presented (Tversky and Kahneman 1986) - though see Pedersen (2017) for an application of this concept to political framing.

${ }^{2}$ For a literal examination of how words are said, see Dietrich, Enos, and Sen (2018), who examine the emotional tone of Supreme Court Justices during arguments using audio data.

${ }^{3}$ This view is contrast to some definitions of what framing is: "A frame in communication can be defined only in relation to a specific issue, event, or political actor," (Chong and Druckman 2007, 106). The validity of definitions like this is often debated (see Cacciatore, Scheufele and Iyengar 2016). It is the author's view that the example provided is unnecessarily restrictive.

${ }^{4}$ The study pre-registration is available at https://osf.io/b96g4/register/565fb3678c5e4a66b5582f67. 
verbs, their Democratic peers are more likely to use future tense verb phrases. There are also stark partisan differences in the use of singular and plural pronouns. Democrats are more likely to use plural pronouns (e.g., 'their', 'our', 'they') and Republicans are more likely to use singular pronouns (e.g., 'his', 'I', 'me').

The results are important and have implications for our understanding of framing and how language is related to identity. First, I demonstrate that framing in political messages is not limited to what is said, but also extends to how it is said. Second, I show that there are a number of similarities between content and style frames: just as the parties emphasize different content (Monroe, Colaresi and Quinn 2008), they also differ their presentation thereof. I also find evidence that content and style frames are often used together and act as complements for one another. The results indicate that the relationship between language and identity is likely stronger than previously thought and that the study of stylistic framing is a worthwhile pursuit.

\section{Theory: Style and Framing}

The style used to communicate an idea is a massively important aspect of language and can be thought of in two ways. First, style can be conceived as existing in specific words. This is the definition commonly used by psychologists (e.g., Mehl, Gosling and Pennebaker 2006; Pennebaker 2013; Slatcher et al. 2007). Tausczik and Pennebaker (2010) identify just 500 style words in English. These are generally function words, like 'it', 'the', or, 'here', which are unrelated to content or requiring contextual understanding between author and reader. This figure constitutes an extremely small proportion of words in an average person's vocabulary. Based on alphabetic forms, 500 words would constitute between $0.6 \%$ and less than $0.01 \%$ of a person's vocabulary (Brysbaert et al. 2016). At the same time, Tausczik and Pennebaker note that "style words make up about $55 \%$ of all the words we speak, hear, and read," $(2010,29)$.

Alternatively, style can be understood as a more general phenomenon: existing not in just function words, but also in content-related words. For instance, content words can take a particular form (e.g., 'ran' vs. 'runs'), or take on different roles and relate to other words in numerous ways (e.g., "she wrote a letter to her friend" vs. "she wrote her friend a letter"). For the purposes of this article, I use the more general understanding of linguistic style and pay specific attention to stylistic variation in language that presents a frame.

Despite the omnipresent nature of style under either definition, the content being communicated and its role in political framing has received far more scholarly attention (e.g., Chong and Druckman 2007; Grimmer 2013b; Grose, Malhotra and Parks Van Houweling 2015; Schonhardt-Bailey 2008). Given that style is ubiquitous in the language we use, the dearth of inquiry concerning style in political framing is 
curious.

It is not the case that style is an uninformative aspect of language either. In a study of political news, Baumer et al. (2015) find that grammatical features (e.g., part of speech, relation, and role), which describe style, are useful predictors of framing. ${ }^{5}$ This suggests that style, or at least its manifestation in grammar, is associated with what lay persons consider to be framing (Baumer et al. 2015). Additionally, research consistently finds that style is related various aspects of peoples' lives: from predicting future health outcomes (Campbell and Pennebaker 2003) to differentiating between liars and truth-tellers (Newman et al. 2003). ${ }^{6}$ While a great deal of research in this area explores the relationship between linguistic style and personality traits, there are few studies concerning style and political identities (see, Cichocka et al. 2016; Pennebaker 2011; Slatcher et al. 2007). And the works that do, tend to be descriptive in nature (Pennebaker 2011; Slatcher et al. 2007), rely on small corpora (Cichocka et al. 2016; Pennebaker 2011; Slatcher et al. 2007), and fail to discuss how style is relevant to framing. Thus, we are left with relatively little knowledge about the role of style in framing and how it relates to political identity. Drawing upon research from the fields of personality, political psychology, and parties I argue that at least two facets of linguistic style are related to stylistic framing in politics: verb tense and grammatical number.

\subsection{Partisan Style in Verb Tense}

One aspect of framing through linguistic style is related to the presentation of time (i.e., temporal framing). This type of framing can be seen everywhere in politics, intersecting with nearly any issue or policy imaginable. No matter if an author or speaker is discussing the naming of a post office or addressing gun violence, they must apply a temporal orientation to that discussion. ${ }^{7}$ Is the issue at hand how gun violence has impacted, is impacting, or could impact citizens' lives? By emphasizing the past, present, or future an author is providing their audience with temporal context. As illustrated by the gun violence example, temporal framing is most clearly observable in verb tense conjugations.

There is reason to suspect that the parties are likely to differ in their use of temporal frames. The Republican Party is largely composed of ideologically conservative "puritans" (Grossmann and Hopkins

\footnotetext{
${ }^{5} \mathrm{As}$ discussed in detail later, part of speech (POS) describes a group of words or tokens that serve related functions in the grammatical structure of a sentence. Relation and role refer to the grammatical relations of a word to other words in a sentence and what role that word plays in the relationship. For example, in the sentence "They defeated death", the POS of 'They' is a non-possessive pronoun. 'They' is related to 'defeated', and its role is as the nominal subject of a verb ('defeated').

${ }^{6}$ While these studies concern the how language can be a reflection of the author or speaker, there is also work on how the structure of a language can impact people. In a recent study, Pérez and Tavits (2017) demonstrate that features of a language can impact people's thinking. They show that when bilingual individuals are interviewed in a futureless language they are more likely to support future-oriented policies than when they are interviewed in a language with future tense. Similarly, earlier work by Athanasopoulos shows that the grammatical representation of number in a language (e.g., plural and singular in English) affects how speakers and learners of that language perceive differences in "the number or amount of non-countable substances" (2006, 89).

${ }^{7}$ At least in languages with distinct tenses (see, Pérez and Tavits 2017).
} 
2016; Lelkes and Sniderman 2016) who tend to prefer maintaining the status quo (Jost, Federico and Napier 2009; Lelkes and Sniderman 2016) and certainty (e.g., Carney et al. 2008). Wanting to keep things the way they are, or even a desire to bring back the "good old days" (Parker 2016), suggests that Republicans are likely to focus on the (certain) past. This has also been exemplified in presidential campaign slogans. Between 1976 and 2016, the Republican nominee's slogan has been past-oriented in five out of eleven campaigns, but just twice for Democrats (1980 and 2004). ${ }^{8}$

Alternatively, the Democratic Party is best understood as a coalition of social groups (e.g., Freeman 1986) seeking some (future) government action (Grossmann and Hopkins 2016). In recent history, the Democratic Party has also been the party of progressivism - seeking to change the status quo. Even the word 'progressivism' is future-oriented, as it implies progress. Social inclusion movements provide the most obvious examples of this (e.g., the civil rights movement of the mid- $20^{\text {th }}$ century; gay marriage; and equal pay for women). Thus it would make sense for Democrats to emphasize the future as they work toward a particular policy or government action that alters the status quo. Again, presidential campaign slogans support this notion: nine of eleven Democratic nominee's slogans invoke the future (see Appendix A).

\section{H1: Verb Tense}

H1a: Republicans will use past tense verbs systematically more than Democrats.

H1b: Democrats will use future tense verbs and phrases implying future actions systematically more than Republicans (e.g., "will work", "should vote").

These intuitions are also supported by works from political psychology, personality, and linguistics. Robinson et al. (2015) finds that conservative news websites are more likely than liberal ones to use past tense verbs, and that the reverse is true of future tense verbs. Additionally, individuals who use more past tense verbs tend to score lower on the Big-Five personality trait of openness (Gill, Nowson and Oberlander 2009; Golbeck et al. 2011; Yarkoni 2010) and are similarly perceived by their peers (Mehl, Gosling and Pennebaker 2006). ${ }^{9}$ At the same time, openness is negatively associated with identifying as a Republican (Cooper, Golden and Socha 2012; Gerber et al. 2012; Mondak 2010; Mondak and Halperin 2008), intention to vote for a Republican presidential candidate (Barbaranelli et al. 2007; Jost 2006), and ideological conservatism (e.g., Carney et al. 2008; Gerber et al. 2011; Jost 2006). Openness is not the only personality trait relevant to verb tense and politics, though. The use of future tense verbs (e.g., 'will', 'could') is negatively related to conscientiousness (Golbeck et al. 2011). Lower levels of conscientiousness are, in turn, associated with an increased likelihood of identifying as a Democrat - among voters (Cooper, Golden and Socha 2012; Mondak

${ }^{8}$ See Appendix A.

${ }^{9}$ See Mondak and Halperin (2008) for an overview of the Big-Five personality traits. 
and Halperin 2008; Gerber et al. 2012) and state legislators (Dietrich et al. 2012) - as well as an intention to vote for a Democratic presidential candidate (Barbaranelli et al. 2007; Jost 2006), and identifying as a liberal (Carney et al. 2008; Gerber et al. 2011; Jost, Federico and Napier 2009).

\subsection{Partisanship and Grammatical Number}

Although it is an important use of linguistic style in framing, temporal orientation is not the only role style has to play. Another concerns the presentation of "subject-scope". The use of subject-scope framing is routine in politics and elsewhere. One might choose to talk about what she is doing or they are doing; what is mine or ours. They might refer to the fire department or firefighters. In other words, an author or speaker can choose to highlight people and entities in an individual or collective manner. This singular-plural distinction is referred to as grammatical number in linguistics. ${ }^{10}$

Just like verb tense, it is reasonable to suspect that the parties differ in their use of subject-scope frames. As Nexon first noted, the Democratic and Republican parties are "different not only in name, program, and coalition components, but also in type," $(1971,717)$. Members of the Republican party are more ideologically aware (Lelkes and Sniderman 2016) and rigid than Democrats (Grossmann and Hopkins 2016). The ideals of individualism and limited government are particularly important to conservatives (Feldman and Zaller 1992) and the Republican Party has put much emphasis on those ideals. Near the start of his acceptance speech at the Republican National Convention in 1984, Reagan proclaimed "[The Democrats'] government sees people only as members of groups; ours serves all the people of America as individuals.". Ten years later, in their Contract with America, Republicans advocated for "the end of government that is too big" and passage of "The Personal Responsibility Act", which promoted, among other things, "individual responsibility" (1994). I expect this partisan and ideological underscoring of individual responsibility to be reflected in Republicans use of singular pronouns (e.g., 'she', 'I', 'his'), which emphasize the individual.

On the other hand, the Democratic Party is much more focused on groups and government's ability to enact policies benefiting them (Grossmann and Hopkins 2016). Indeed, the Democratic Party often contrasts itself with the Republican Party on this front. For example, during Obama's 2008 acceptance speech, he mocked the Republican emphasis on individualism and differentiated the Democratic Party from that view:

Born into poverty? Pull yourself up by your own bootstraps even if you don't have boots. You're on your own. ...You see, we Democrats have a very different measure of what constitutes progress in this country.

Concurrently, research shows that Democrats are less likely than Republicans to see government programs

\footnotetext{
${ }^{10}$ Number is formally defined as a "grammatical category of nouns which marks quantity" and "can also be applied to other parts of speech... through agreement," (Bussmann 2006).
} 
(e.g., public schools) as being particularistic (Lelkes and Sniderman 2016). Lelkes and Sniderman also find Democrats who perceive a policy as being particularistic or societal are more likely to support increased government funding of that policy than Republicans holding that same view $(2016,839)$. This group-centric structure of the Democratic Party is expected to be manifest in a pronounced use of plural pronouns (e.g., 'they', 'we', 'our'), which highlight the collective and groups.

\section{H2: Pronoun Number}

H2a: Democrats will use plural pronouns systematically more than Republicans.

H2b: Republicans will use singular pronouns systematically more than Democrats.

As the fire department and fire fighters example at the beginning of this subsection demonstrates, it is possible that this link between partisan values and grammatical number extends beyond pronouns - being observable across all noun classes. For example, it may be the case that Republicans are more prone to frame discussions around singular noun subjects (e.g., "the fire department") instead of plural noun subjects (e.g., "firefighters"). This would make sense as nouns typically follow pronouns as objects in a sentence. For example, if I use a numbered pronoun, the noun(s) that follow will often match that number. In the non-possessive case this might look like "we are researchers" vs. "I am a researcher". This can also be done with possessive pronouns: "their jobs" vs. "her job". ${ }^{11}$

\section{H3: Noun Number}

H3a: Democrats will use plural nouns (of all types) systematically more than Republicans.

H3b: Republicans will use singular nouns (of all types) systematically more than Democrats.

\section{Data}

I evaluate the hypotheses discussed above using a new collection of Senate press releases. Press releases were scraped for all sitting senators at the time of data collection: November, 2016. For each senator, I collected every press release published on their site, regardless of the publication date. This resulted in a collection of over 180,000 web pages. These web pages were then parsed and the press release text, along with meta-information like publication date and title, was extracted. Due to the variance in length of Senate membership, I rely on press releases published during the $114^{\text {th }}$ Congress $(2015-2016)$ for confirmatory analyses. Documents containing fewer than 25 tokens are dropped from the analysis and one document that

\footnotetext{
${ }^{11}$ There are, of course, many exceptions to this type of number matching (e.g., "our goal is clear").
} 
could not be annotated was dropped. ${ }^{12}$ The resulting corpus contains 48,527 documents. ${ }^{13}$

Press releases provide a number of benefits over other possible mediums (see, Grimmer 2013a,b). First, Senate offices have enormous control over the subject, content, and timing of press releases. This makes them particularly well-suited to message crafting. Second, they are produced extremely regularly, with roughly 72 being published per day on average. ${ }^{14}$ This means that there is a relatively large body of text for each Senator and a fine temporal granularity, which can strengthen validity checks (Grimmer and Stewart 2013). The same cannot be said of other communication methods (e.g., floor speeches or campaign fund raising emails). Third, press releases are unique in that they provide a relatively direct channel for senators to communicate with their constituents. As noted by Grimmer $(2010 ; 2013 b)$, it is common for local news outlets to publish press releases with minimal, if any, editing. Finally, press releases are unique in their versatility. Senators can use them to discuss current issues in Congress or the government more generally defined. They also use them to announce events they are involved in or hosting: such as constituency meet-ups or office hours. And they can use them to claim credit for allocations alloted to their constituents. Although some of these functions are suitable for other mediums like floor speeches, others are not: for instance, Grimmer finds that, while " $36 \%$ of press releases contain credit claiming about appropriations", just $4 \%$ of Senate floor speeches do the same $(2013 a, 627)$.

Because senators are not writing their own press releases, the analysis is actually of communications with the constituency by senators' offices. While this would likely be problematic for studies of style related to other traits (e.g., age or sex), my focus on partisanship makes the distinction between senator and author less problematic. ${ }^{15}$ Still, I am making the weak assumption that each press release is written as if the author and senator are of the same party. ${ }^{16}$ Talking points provided to representatives by their respective party help to ensure consistent messaging across the party (Lipinski 2004). Also, evidence suggests that authors (i.e., staff) and senators are actually co-partisans a lot of the time: "Many staff interviewed... commented that they would not hire someone who did not have strong credentials as a member of the appropriate political party," (Romzek and Utter 1997, 1267). Finally, regular oversight by more senior staff (e.g., a communications director) in reviewing documents before release places a tight constraint on the author. ${ }^{17}$

\footnotetext{
$\overline{12}$ This document was from Senator Cardin (D-MD); Nov. 11, 2015. The error was due to a long list of letter signatories that caused the tagging program to run out of RAM.

${ }^{13}$ The full set of raw HTML pages, the parsed, cleaned, tagged, and lemmatized texts, and final topic model data are available at https://dataverse.harvard.edu/dataset.xhtml?persistentId=doi:10.7910/DVN/17GRCF. Corresponding documentation and code can be found at https://github.com/rymc9384/Party0fSpeech.

${ }^{14}$ Using an older corpus, Grimmer $(2013 a, 527)$ finds significantly fewer press releases: 58 per day.

${ }^{15}$ In the case of age, staffers - especially those in less senior positions - tend to be much younger than the representative they serve, thus obscuring the tie between the representative's age and the language used in their press releases. As for sex, evidence suggests that female representatives in Congress are no more likely to have female press secretaries than male representatives (Wilson and Carlos 2014). Again, this could impact any inferences drawn from such an analysis.

${ }^{16}$ Note that because the focus of this study is on style, this assumption does not imply that authors are dutiful agents to the senator they work for in terms of accurately presenting the senator's position about any given issue.

${ }^{17}$ An employee handbook from one representative's office includes "Unauthorized communication with press, written statement,
} 


\section{Methods}

In order to examine the differential use of verb tense, pronoun number, and noun number I model the text in three ways. First, I annotate the text for part-of-speech (POS) tags. Using the resulting tags, the text is then also lemmatized. ${ }^{18}$ Second, I apply a single-membership topic model (see Grimmer 2010) to the text in order to capture any potential heterogeneity in partisan differences across issue contexts. Finally, I model intra- and inter-topic partisan differences using the "Fightin' Words" model (Monroe, Colaresi and Quinn 2008).

\subsection{Parts of Speech}

The first step toward analyzing partisan differences in grammar is to extract grammatical features from the text. Specifically, the text needs to be annotated for part of speech (POS), also known as "word class". This type of annotation, commonly known as POS tagging or "tagging", is a classification problem where the goal is to assign a word/token to the correct POS: e.g., transforming "[TOKEN, TOKEN, TOKEN]" to "[(TOKEN,TAG), (TOKEN,TAG), (TOKEN,TAG)]".

A POS describes a group of words or tokens that serve related functions in the grammatical structure of a sentence. These "word classes" (i.e., parts-of-speech) can be defined in a number of ways: from simple (e.g., verb vs. noun) to extremely complex (e.g., continuous-aspect, present-tense verb - "She is planning" vs. perfect-aspect, past-tense verb - "She had planned"). Defining the set of possible "word classes" is an important choice when annotating the text and there are seemingly infinite ways to do so. Fortunately, there is a movement toward using a small group of standard POS tagsets including the "Universal Part-ofSpeech" (UPOS) tagset (Petrov, Das and McDonald 2011) and the "Penn Treebank" (PTB) tagset (Marcus, Marcinkiewicz and Santorini 1993). ${ }^{19}$ For the purposes of this study, I rely on the more fine-grained PTB tagset. Table 1, below, provides an overview of the PTB tagset, excluding tags for punctuation.

\subsection{Annotating the Text}

Having chosen a set of POS tags to work with, the next step is to annotate the text using those tags. This process of tagging transforms the tokenized text (e.g., ['She', 'went', 'to', 'the', 'conference']) into a more feature rich version of itself (e.g., [('She',PRP), ('went',VBD), ('to',TO), ('the',DT), ('conference',NN)]). Of course it would extremely laborious to label every word in the corpus by hand. Instead, it is much more

\footnotetext{
personal appearances, etc., without direct clearance," in a list of staff misconduct (Romzek 2000, Appendix B).

${ }^{18}$ Lemmatizing text is similar to the commonly used method of stemming. However, instead of cutting off the end of words based on a set of rules, lemmatization attempts to convert words back to their root word: e.g., 'am' to the root 'be'. This can be useful for investigating semantics.

${ }^{19}$ The PTB tagset has 36 tags unrelated to punctuation. With just 12 tags in total, the UPOS list is much more coarse.
} 
Table 1: Non-Punctuation, Penn Treebank POS Tags

\begin{tabular}{|c|c|c|c|}
\hline & Tag & Part-of-speech & Example \\
\hline 1. & $\mathrm{CC}$ & Coordinating conjunction & and, but \\
\hline 2. & $\mathrm{CD}$ & Cardinal number & first, 12 \\
\hline 3. & DT & Determiner & the, those, an \\
\hline 4. & EX & Existential there & there are rules \\
\hline 5. & FW & Foreign word & correr, courir \\
\hline 6. & IN & Preposition or subordinating conjunction & on, from, of \\
\hline 7. & JJ & Adjective & large, small \\
\hline 8. & JJR & Adjective, comparative & larger, smaller \\
\hline 9. & JJS & Adjective, superlative & largest, smallest \\
\hline 10. & LS & List item marker & 1), ii) \\
\hline 11. & MD & Modal & would, should \\
\hline 12. & $\mathrm{NN}$ & Noun, singular or mass & car, card, joy \\
\hline 13. & NNS & Noun, plural & cars, cards \\
\hline 14. & NNP & Proper noun, singular & Denver, Iraq \\
\hline 15. & NNPS & Proper noun, plural & Republicans, Democrats \\
\hline 16. & PDT & Predeterminer & all parties involved \\
\hline 17. & POS & Possessive ending & 's \\
\hline 18. & PRP & Personal pronoun & she, he, they \\
\hline 19. & PRP\$ & Possessive pronoun & hers, his, mine \\
\hline 20. & $\mathrm{RB}$ & Adverb & quickly, slowly \\
\hline 21. & $\mathrm{RBR}$ & Adverb, comparative & quicker, slower \\
\hline 22. & RBS & Adverb, superlative & quickest, slowest \\
\hline 23. & $\mathrm{RP}$ & Particle & look up the meaning \\
\hline 24. & SYM & Symbol & $\&, \%$ \\
\hline 25. & $\mathrm{TO}$ & to & where to next \\
\hline 26. & $\mathrm{UH}$ & Interjection & ouch, oh, golly \\
\hline 27. & $\mathrm{VB}$ & Verb, base form & be, run, burn \\
\hline 28. & VBD & Verb, past tense & was, ran, burned \\
\hline 29. & VBG & Verb, gerund or present participle & being, running, burning \\
\hline 30. & VBN & Verb, past participle & burnt \\
\hline 31. & VBP & Verb, non-3rd person singular present & You run \\
\hline 32. & VBZ & Verb, 3rd person singular present & She runs \\
\hline 33. & WDT & Wh-determiner & which, whichever \\
\hline 34. & WP & Wh-pronoun & what, whom, who \\
\hline 35. & WP\$ & Possessive wh-pronoun & whose \\
\hline 36. & WRB & Wh-adverb & when, where, why \\
\hline
\end{tabular}

Note: These are the 36 non-punctuation tags from the full PTB tagset (48 tags)

Adapted from: https://cs.nyu.edu/grishman/jet/guide/PennPOS.html and https ://www. clips . uantwerpen.be/pages/mbsp-tags. 
efficient to use a modeling approach.

In this paper, I rely on the "Cyclic Dependency Network" model described by Toutanova et al. (2003). ${ }^{20}$ I use a pre-trained version of the model, made available by the Stanford CoreNLP group. The pre-trained model is nearly identical to the original from Toutanova et al. (2003), who reported $97.28 \%$ token level accuracy on test data from the Wall Street Journal portion of the Penn Treebank corpus. ${ }^{21}$ The model's high out-of-sample accuracy, combined with similarity between the text used for training and press releases the model is predicting on, provides confidence that this approach yields reliable results.

I tag all documents from the 113th (2013-2014) and 114th (2015-2016) Congresses, though only documents from the latter are used in confirmatory analyses. The texts are tokenized at the sentence level, using a pre-trained Punkt tokenizer (Kiss and Strunk 2006), and the word level - according to rules used for the Penn Treebank data. Both of these operations are done with the NLTK module in python (Bird, Klein and Loper 2009). The resulting word-tokenized sentences are used as input for the tagger. ${ }^{22}$

\subsubsection{Post-processing the Annotations}

A manual inspection of annotated documents from various senators revealed that all POS tags were accurately assigned, except for one. Parentheses, ubiquitous in the press releases, were being incorrectly tagged as proper nouns. This was likely due to their place in the beginning of press releases, where they were surrounded by actual proper nouns: e.g., "Today U.S. Sen. Lamar Alexander (R-Tenn.) said that..." (Alexander 2016). ${ }^{23}$

After fixing these tags, the texts are then lemmatized using the program morpha (Minnen, Carroll and Pearce 2001). Lemmatization is similar to the common practice of stemming. While stemming reduces words to their stem by cutting off the end and substituting some vowels (e.g., 'flies' to 'fli'), lemmatization attempts to reduce words to their root (e.g., 'am' to 'be'). This process can be useful when one wants to examine base word usage.

As Table 1 illustrates, the Penn Treebank tagset does not contain all of the word classes that I am interested in. While there are two tags related to past tense verbs (VBD and VBN), there is no tag for a "future tense" verb. And although nouns and proper nouns are conveniently split into plural and singular

\footnotetext{
${ }^{20}$ This was a secondary choice, as specified in the pre-registration. I was not able to procure access to the Penn Treebank WSJ data, which prohibited me from properly training a variant on the Bidirectional LSTM-CRF model put forth by Huang, Xu and $\mathrm{Yu}$ (2015). Code for that model is, however, available at https://github.com/rymc9384/Party0fSpeech/tree/master/ 02-pos_tagging/bilstm_char and can be trained on a sample of the WSJ data available in the NLTK python library (Bird, Klein and Loper 2009).

${ }^{21}$ The accuracy reported in the CoreNLP documents is slightly higher than in the original paper due to minor changes in the Stanford CoreNLP releases. I used version 3.8.0, released June 19 ${ }^{\text {th }}, 2016$. Also, see Manning (2011). Details about the model can be found in Appendix B.

${ }^{22}$ Tagging failed for four documents: Senators Brown (1), Cardin (1), and Casey (2). These documents contained long lists of letter signatories, which caused the program to overrun RAM limits. Only the document from Senator Cardin was from the 114th Congress and it is excluded from confirmatory analyses.

${ }^{23}$ All parentheses were manually assigned to the correct punctuation tag using a regular expression substitution.
} 
(NN, NNS, NNP, and NNPS), pronouns are not delineated by number. The tags PRP and PRP $\$$ only indicate whether the pronoun is possessive or not (e.g., "she/PRP" vs. "her/PRP\$"). To overcome this issue, I adapt the existing tags to fit my needs.

Verbs First, there are multiple past-tense nouns and no single tag for "verb phrases implying future action". I thus create my own 'VBPAST' and 'VBFUT' tags for these cases, as shown in Table 2. The 'VBPAST' tag is an aggregation of both past tense verb tags from the PTB tagset: 'VBPAST' = 'VBD' + 'VBN'. Alternatively, the 'VBFUT' tag is generated from sequences of two and three tokens. Focusing on the tags, a sequence of 'MD VB' or 'MD RB VB' is converted to 'VBFUT'. These sequences of tags represent a modal (e.g., 'will', 'can', 'should') followed by an affirmative or negated present tense verb (e.g., 'vote', 'not vote'). Although these two tag sequences do not fully encapsulate the concept of a "future tense", I believe that they are a useful approximation. Other tag sequences were considered, but were more ambiguous to tense. $^{24}$

Table 2: New Verb Tense Tags

\begin{tabular}{lclll}
\hline & POS & New Tag & Components & Example \\
\hline 1$)$ & Past tense verb & VBPAST & {$[$ VBD, VBN] } & 'voted', 'cast' \\
2) & "Future" tense verb & VBFUT & {$[$ MD VB, MD RB VB] } & 'will provide', 'will not help' \\
\hline
\end{tabular}

Pronouns Like verbs, the existing tags for pronouns from the PTB tagset do not quite fit my needs. They do not delineate between singular and plural pronouns, only possessive and not. I remedy this by again creating my own tags: 'PRPSING' and 'PRPPLUR'. Unlike the verb tense tags, however, splitting pronouns into new singular and plural tags depends on the tag and the token it describes. I only consider tokens that have already been tagged as pronouns, which could be possessive or not. How pronoun tokens are assigned to the new singular or plural tags is described in Table 3 .

Table 3: New Pronoun Number Tags

\begin{tabular}{ccll}
\hline POS & New Tag & Non-possessive Tokens & Possessive Tokens \\
\hline 1) Singular pronoun & PRPSING & $\begin{array}{l}\text { i, me, it, he, she, her, him, this, that, } \\
\text { myself, herself, himself, yourself }\end{array}$ & his, its, hers, mine \\
2) Plural pronoun & PRPPLUR & $\begin{array}{l}\text { we, us, they, them, these, those, } \\
\text { ourselves, yourselves, themselves }\end{array}$ & our, ours, their, theirs \\
\hline
\end{tabular}

\footnotetext{
${ }^{24}$ For example, one considered sequence was 'VB VBG TO'. The initial thought was to capture instances like "I_PRP $a m_{-} V B$ going_VBG to_TO ...". However, such a sequence would also capture "I_PRP am_VB seeing_VBG to_TO it_PRP that_WDT he_PRP is_VB reprimanded_VBD". In the latter example, 'that' may alternatively, and incorrectly, be tagged as 'IN' in the PTB corpus (Manning 2011, 173).
} 
Notably absent from Table 3 is the second-person personal pronoun 'you' and a selection of its conjugations: e.g., 'your', 'yours', and 'ya'. I exclude these tokens because they can be used as singular or plural pronouns. While it is possible to disambiguate these words - with coreference resolution (see, Clark and Manning 2016) - this is a relatively difficult task compared to tagging. Another noteworthy decision in generating the lists of singular and plural pronouns is the inclusion of 'they' and 'their' in the plural category. These are now allowable as non-gendered singular pronouns in style guides (Associated Press 2017). I, however, include them in the plural category because at the time these press releases were authored, AP style was to not use 'they' or 'their' as singular pronouns. ${ }^{25}$

Nouns Finally, I combine number delineated tags from the PTB tagset and the new numbered pronoun tags (see Table 3) to form the new singular and plural tags for all noun types. Table 4 details how the new noun tags are created for the confirmatory analyses of my hypotheses concerning singular and plural noun usage (H3a and $\mathrm{H} 3 \mathrm{~b})$.

Table 4: New Noun Number Tags

\begin{tabular}{lcll}
\hline & POS & New Tag & Components \\
\hline 1) & Singular Nouns & NNSING & [NN, PRPSING, NNP] \\
2) & Plural Nouns & NNPLUR & {$[$ NNS, PRPPLUR, NNPS] } \\
\hline
\end{tabular}

As shown in the right-hand column of Table 4, each of these tags is made up of singular or plural common nouns, pronouns, and proper nouns.

\subsection{Classifying Topics}

The second modeling step is focused on disambiguating the press releases with respect to topic. When examining a corpus with content that is very diverse, it is often useful to use some sort of document clustering algorithm (Greene and Cross 2017; Grimmer 2010, 2013b; Monroe, Colaresi and Quinn 2008; Quinn et al. 2010). Modeling documents' topics before analyzing the data can improve the quality of findings in two ways. First, grouping texts based on their content reduces the likelihood that one (or a small set) of topics drive the overall results. Second, it allows for the examination of differences at a more granular level, which can, in turn, add nuance to the findings. And while I do not have any topic specific hypotheses concerning style, classifying the texts by topic is useful for exploratory analyses.

Unlike a variety of other document types (e.g., news transcripts or academic articles), press releases are almost exclusively focused on a particular topic (Grimmer 2010, 2013b). The typical topic models - e.g.,

\footnotetext{
${ }^{25}$ The change was announced by AP on March 24, 2017, well after the latest publication date of any press release in my data.
} 
Latent Dirichlet Allocation (LDA) and its extensions (Blei and Lafferty 2006; Blei, Ng and Jordan 2003), and Non-negative Matrix Factorization (NMF; Paatero and Tapper 1994) - that assume documents are generated based on a mixture of topics then seem ill-suited to the task. Instead, I sort documents into topics using the single membership "Expressed Agenda" model (Grimmer 2010, 2013b), which assumes documents are generated from just one topic. ${ }^{26}$

For the purposes of this article, I rely on a model estimated under the assumption that there are 45 topics in the texts. This model was selected based on a series of quantitative and qualitative evaluations (see Grimmer 2010; Quinn et al. 2010). I label each topic using the ten word-stems most strongly associated with the topic - by mutual information - and reading a random sample of ten documents with a high probability of assignment to the topic (Grimmer 2010). These labels and other topic descriptives can be found in Table 5 , below. Documents are assigned to the topic with the highest probability of generating the document. Like Quinn et al. (2010, 215), I find that this assignment procedure results in minimal information loss: over $99 \%$ of documents are assigned to a single topic with greater than $95 \%$ probability. ${ }^{27}$

\footnotetext{
${ }^{26}$ Quinn et al. (2010) offer another single membership model, though theirs is more concerned with the temporal dynamics of topics.

${ }^{27}$ More information about estimating and evaluating the model can be found in Appendix C.
} 
Table 5: Topic Labels and Descriptives

\begin{tabular}{|c|c|c|c|}
\hline Topics & Stems & $\%^{a}$ & Notes \\
\hline 1) Localistic & counti, state, street, feder, commun & $1.23 / 1.83$ & incl. funding for local projects, meet and greets, town halls \\
\hline 2) Education 1 (funding) & student, colleg, educ, school, program & $1.78 / 1.07$ & incl. higher ed and retraining \\
\hline 3) Chemical Safety Bill & safeti, chemic, state, transport, year & $1.84 / 2.36$ & The Frank R. Lautenberg Chemical Safety for the 21st Century Act \\
\hline 4) Guns & gun, violenc, firearm, law, check & $0.93 / 2.02$ & incl. gun violence, trafficking, and background checks \\
\hline 5) EPA & epa, state, environ, mine, agenc & $1.25 / 1.62$ & \\
\hline 6) Budget & budget, year, spend, debt, congress & $1.84 / 2.42$ & incl. spending bill and program funding \\
\hline 7) Nat'l Issues (general) & state, unit, refug, nation, year & $4.32 / 1.66$ & incl. PPACA, int'l relations, opioids, symbolic \\
\hline 8) Iran Deal & iran, nuclear, agreement, deal, sanction & $2.77 / 2.71$ & incl. N. Korea \\
\hline 9) Immigration & immigr, law, state, enforc, illeg & $1.25 / 2.65$ & incl. sanctuary cities, refugees in US and EU \\
\hline 10) FCC & internet, servic, religi, freedom, govern & $0.77 / 2.69$ & incl. net neutrality \\
\hline 11) Airport Funding/Safety & airport, fund, feder, faa, aviat & $1.57 / 1.03$ & \\
\hline 12) HUD/HHS & hous, fund, program, lead, famili & $1.16 / 1.03$ & incl. funding, regulation \\
\hline 13) Health Care & health, care, servic, provid, act & $4.70 / 2.27$ & incl. PPACA, medicaid/are, planned parenthood, awareness, rural care \\
\hline 14) $\mathrm{VA}$ & veteran, care, servic, health, program & $4.21 / 1.43$ & incl. health care, services, and benefits \\
\hline 15) Oil And Gas & oil, crude, safeti, pipelin, rail & $0.82 / 1.43$ & incl. Deepwater Horizon anniversary, oil train derailments, fracking \\
\hline 16) Banking/Finance & bank, export, busi, import, financ & $0.84 / 1.35$ & incl. regulation and import-export bank \\
\hline 17) Terrorism & terrorist, attack, state, detain, guantanamo & $2.08 / 2.90$ & incl. rememberance-military and Guantanamo \\
\hline 18) Symbolic & nation, american, honor, year, famili & $5.00 / 5.95$ & incl. rememberance, holidays, accepting positions, commemoration \\
\hline 19) Research & research, nation, univ, fund, develop & $2.04 / 2.33$ & incl. funding, disease, cancer, defense \\
\hline 20) Sexual/Domestic Violence & sexual, violenc, assault, victim, domest & $0.87 / 1.16$ & incl. universities and military \\
\hline 21) Consumer Protection & consum, protect, product, compani, inform & $2.02 / 3.20$ & incl. automotive, finance, FCC, and food \\
\hline 22) EMS/Fire Dept. Funding & fire, depart, firefight, grant, fund & $1.94 / 0.80$ & incl. fire dept., first responders \\
\hline 23) Small Business & busi, small, help, act, job & $1.51 / 0.97$ & incl. jobs, PPACA, regulation, and honor \\
\hline 24) Trade & trade, american, worker, agreement, state & $1.91 / 2.27$ & incl. steel and manufacturing \\
\hline 25) Jobs & employ, worker, job, work, manufactur & $2.45 / 2.10$ & incl. worker protections, job creation \\
\hline 26) Education 2 (K-12) & school, educ, student, state, program & $2.55 / 1.66$ & incl. no child left behind, testing, school choice \\
\hline 27) Legislation & act, legisl, feder, law, american & $4.65 / 2.21$ & incl. bill introduction, (co)sponsorship \\
\hline 28) Defense & forc, nation, defen, air, militari & $3.95 / 2.71$ & incl. rememberance, funding, bases, Afghanistan, Syria, veterans \\
\hline 29) Judicial & nomin, court, presid, judg, suprem & $2.17 / 2.99$ & incl. Garland, appointments, rulings \\
\hline 30) President & presid, american, peopl, obama, state & $4.29 / 10.66$ & incl. state of union, admin budget, Iran, foreign relations \\
\hline 31) Nat'l Parks/Lands & lake, land, great, nation, protect & $2.04 / 2.25$ & incl. agriculture, outdoor recreation, dept. of interior \\
\hline 32) Infrastructure & water, state, fund, commun, project & $1.35 / 0.72$ & incl. transportation, hurricane Sandy, WOTUS, drinking water \\
\hline 33) Drugs & drug, opioid, addict, prescript, abus & $2.92 / 2.65$ & incl. opioids and prices \\
\hline 34) Agency Oversight & rule, regul, state, feder, water & $1.85 / 2.44$ & incl. hearings, investigations, reaction to executive actions \\
\hline 35) Pork Spending & fund, project, million, feder, program & $4.39 / 1.56$ & \\
\hline 36) Rural Services & program, commun, support, fund, help & $3.96 / 1.33$ & incl. internet, hospitals/health care, land regulations \\
\hline 37) Law Enforcement & offic, polic, law, enforc, commun & $2.19 / 1.37$ & incl. funding, rememberance, honor, benefits, shootings (by and of) \\
\hline 38) Investigations & depart, report, gener, state, letter & $2.89 / 5.15$ & incl. Hillary Clinton, use of funds \\
\hline 39) Student Loans & student, loan, colleg, program, educ & $0.58 / 0.97$ & \\
\hline 40) Homeland Security & secur, nation, homeland, inform, feder & $2.56 / 1.94$ & incl. cyber security, ISIS/terrorism \\
\hline 41) Children & traffick, human, victim, sex, state & $0.95 / 1.79$ & incl. trafficking, sex crimes, protection, human rights \\
\hline 42) Taxes & tax, credit, year, famili, act & $1.60 / 1.33$ & \\
\hline 43) Energy & energi, state, nation, help, develop & $2.23 / 1.20$ & incl. subsidies, funding for tech, clean/renewable sources \\
\hline 44) Zika & zika, viru, fund, health, state & $0.98 / 1.83$ & incl. funding, health care \\
\hline 45) Climate Change & climat, chang, state, clean, carbon & $0.78 / 2.00$ & incl. clean energy, carbon emissions, land conservation \\
\hline
\end{tabular}

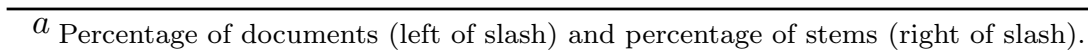


Although reading the random sample of documents while labeling the topics in-itself serves as a check on model validity, there are other methods of validation (see Grimmer 2010; Grimmer and Stewart 2013; Quinn et al. 2010). One commonly employed method is to compare topic frequencies over time with known external events. I follow this tradition, focusing on the "Iran Deal" topic in Figure 1.

Figure 1: "Iran Deal" Press Releases and Events

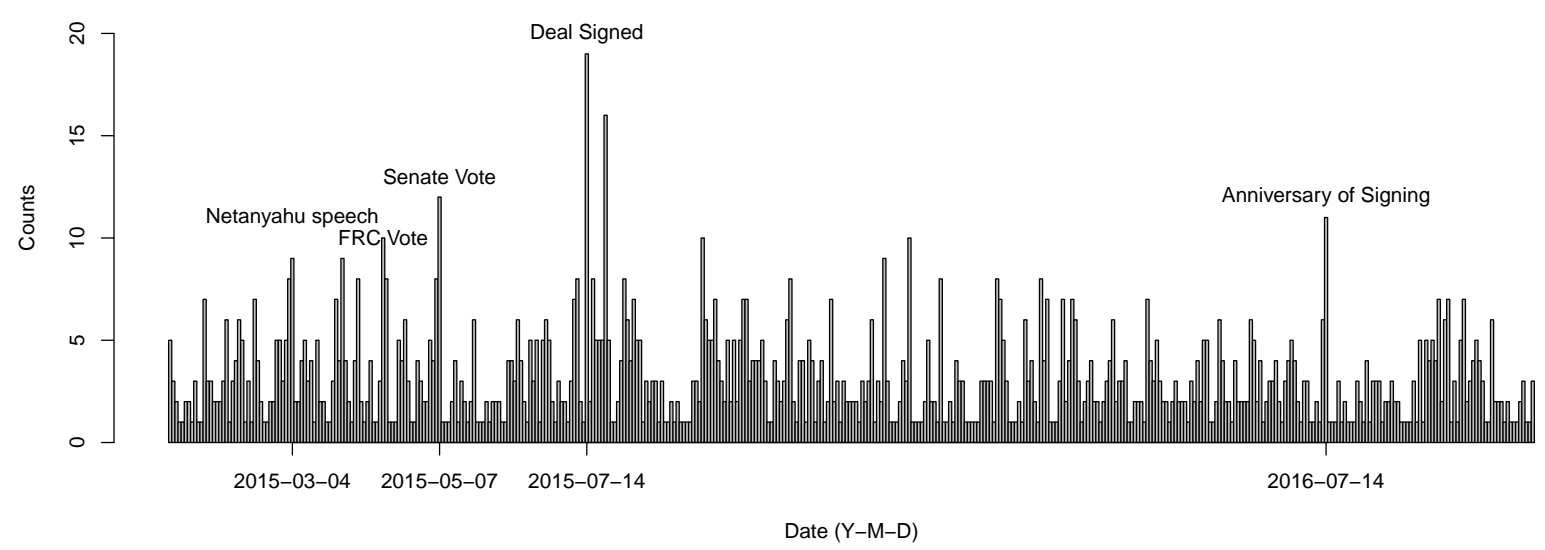

Note: The Foreign Relations Committee (FRC) and Senate votes concerned legislation introduced by Sen. Bob Corker (R-TN) to mandate congressional review of a nuclear deal with Iran.

There is clear relationship between major events concerning Iran's nuclear program and the number of press releases put out from the "Iran Deal" topic. Early spikes in March of 2015 correspond with Israel's Prime Minister Benjamin Netanyahu delivering a speech to a joint session of Congress and an announcement that Sen. Corker's (R-TN) bill would be considered the next week. Subsequent rises occur during key votes on that legislation, the signing of a nuclear deal in Vienna, and the anniversary of that signing. This correlation in events and the number of documents assigned to the "Iran Deal" topic, combined with reading ten documents for each topic, provides evidence in favor of the model's validity.

\subsection{Assessing Differences}

The final step in the analysis is to evaluate the differential use of grammatical features between the parties. While there are many approaches to doing this, most have been shown to have shortcomings in one or more situations. For instance, simple metrics like frequencies and proportions tend to reflect common words as being the most partisan (Monroe, Colaresi and Quinn 2008). More complex measures can produce equally poor results. Monroe, Colaresi and Quinn note that the oft used TF-IDF method (Manning and Schütze 1999, 541-44) provides rather nonsensical estimates when used for this purpose: "The most partisan words are the words spoken the most by one party, while spoken not once by the other," $(2008,381)$. Even with a 
large corpus and topic sub-corpora, the "most" partisan words using this measure likely appear fewer than 100 times (Monroe, Colaresi and Quinn 2008, 383).

As an alternative to these and other problematic methods, I use the "Fightin' Words" model (Monroe, Colaresi and Quinn 2008). This model allows for the selection and evaluation of differential word use by particular groups using smoothed log-odds ratios. Essentially, the model is very similar to fitting a logistic regression "of the binary choice, word $w$ versus any other word," on group indicator(s) (Monroe, Colaresi and Quinn 2008, 385), except that the "Fightin' Words" model also allows for the incorporation of priors that can induce estimate shrinkage. ${ }^{28}$ However, the primary statistic of interest in this model is not the estimated difference (i.e., the group coefficient in the regression example). Instead, the focus of the model is on a test statistic, denoted $\zeta_{w}^{(i-j)}$ for groups $i$ and $j$ by Monroe, Colaresi and Quinn (2008), which is basically the $z$-score on the group coefficient in the regression example. This is beneficial for identifying features that are distinctly associated with one group or another by accounting for the variance around difference estimates.

For this paper, following the regression example, the binary choice is between a POS tag $n$-gram, $w$, and any other tag $n$-gram, where the length of an $n$-gram can be between one and three, inclusive. This choice is modeled as a function of senator partisanship (i.e., Republican or Democrat). ${ }^{29}$ However, in exploratory analyses and robustness checks a "word" $w$ can be a sequence of lemma-tag pairs (e.g., ('be',VBN), [('will',MD), ('help',VB)], or [('i',PRP), ('would',MD), ('note',VB)]). ${ }^{30,31}$

I use the Fightin' Words model to analyze partisan differences in two ways. First, for confirmatory analyses, I ignore what topic documents are assigned to. I do this because I have no a priori hypotheses concerning differences within a given topic. ${ }^{32}$ Additionally, since I cannot generate a proper prior on $n$-gram probabilities from external data here, I use a very diffuse prior (see, Monroe, Colaresi and Quinn 2008). The second approach accounts for topic, so the association between a POS $n$-gram and a party is estimated within each topic. For these analyses I use data from 44 topics not being modeled to generate my priors and shrinks estimates toward 0, implying no differences. Under this specification, differences between the parties must be especially stark in order for those differences to be observed. More information about the models and priors can be found in Appendix D.

To accommodate differences in prior specification for the inter- and intra-topic analyses, I use different

${ }^{28}$ More details about the method can be found in Monroe, Colaresi and Quinn (2008, 382-90).

${ }^{29}$ Independents are assigned to the party with whom they caucus. In this data, that means that Senators King (I-VT) and Sanders (I-VT) are treated as though they are Democrats.

${ }^{30}$ I use $n$-grams between one and three so that I can capture the "future" tense verbs without distorting the counts of their components. If the multi-token sequences are simply replaced in the texts before building the vocabulary, counts of their components will be distorted - though only by a small amount.

${ }^{31}$ In most robustness and exploratory analyses I use unigram counts. This is computationally easier and the difference in estimates caused by only using unigram token counts is only noticeable at the second decimal place.

${ }^{32}$ Further, developing these hypotheses for the pre-registration would have been very difficult given that I could not know what topics the Expressed Agendas model (Grimmer 2010) would yield. 
significance cut-offs. For the inter-topic models, using the notation of Monroe, Colaresi and Quinn (2008), $\left|\zeta_{w}^{(i-j)}\right| \geq 4.42$ is considered significant, and for intra-topic models the cutoff is $\left|\zeta_{w}^{(i-j)}\right| \geq 3.29$. For reference, these cut-offs correspond to p-values of 1e-6 and .001 for a two-tailed z-score, respectively. I use the more stringent standard when evaluating differences across the entire corpus because those analyses rely on the uninformative prior.

\section{Results}

Recall that I generated three sets of hypotheses about the relationship between partisanship and three types of word classes that facilitate temporal or subject-scope framing. First, I hypothesized that Republican press releases are more likely to use past tense verbs than Democratic ones, and that the opposite is true for future tense verbs. My second set of hypotheses anticipate that the odds of using plural pronouns are higher if the release comes from a Democrat, but that singular pronouns are more likely to appear in Republican documents. Finally, I expected the relationship between partisanship and pronoun number would extend to all noun types. All of these confirmatory hypotheses concern differences between parties across the entire corpus (i.e., ignoring topic). As such, I test each set using the inter-topic Fightin' Words model with an uninformative prior fit to POS tag uni, bi, and trigrams. The results of those models are displayed in the top half of Table 6. Summaries of the intra-topic models, which use a conservative prior, are presented in the bottom half of the table. I proceed with a description of my findings on verb tense. ${ }^{33}$

Table 6: Word Class Relationships (Number and Tense)

\begin{tabular}{l|cccccc}
\hline & $\begin{array}{c}\text { Past Tense } \\
\text { Verbs }\end{array}$ & $\begin{array}{c}\text { Future Tense } \\
\text { Verbs }\end{array}$ & $\begin{array}{c}\text { Singular } \\
\text { Pronouns }\end{array}$ & $\begin{array}{c}\text { Plural } \\
\text { Pronouns }\end{array}$ & $\begin{array}{c}\text { Singular } \\
\text { Nouns }\end{array}$ & $\begin{array}{c}\text { Plural } \\
\text { Nouns }\end{array}$ \\
\hline $\begin{array}{l}\text { Inter-Topic Sig. Relation } \\
\zeta_{w}^{(R-D)}\end{array}$ & GOP & DEM & GOP & DEM & - & DEM \\
& $(26.41)$ & $(-7.14)$ & $(69.62)$ & $(-10.22)$ & $(2.50)$ & $(-68.51)$ \\
\hline$n(\%)$ Topics w/ Sig. Relation & 19 & 3 & 42 & 10 & 8 & 41 \\
\begin{tabular}{l} 
in Hypothesized Direction \\
\hline
\end{tabular} & $(42 \%)$ & $(7 \%)$ & $(93 \%)$ & $(22 \%)$ & $(18 \%)$ & $(91 \%)$ \\
\hline
\end{tabular}

Note: Positive(Negative) $\zeta_{w}^{(R-D)}$ values indicate an association with Republican(Democratic) press releases. For the

inter-topic analyses (top rows), $\left|\zeta_{w}^{(R-D)}\right| \geq 4.42$ is considered a significant difference between the parties. This threshold is dropped to 3.29 in the intra-topic analyses (bottom rows). The relaxed critical value in the intra-topic analyses reflects the use of informative priors that regularize difference estimates toward zero in those models.

\footnotetext{
${ }^{33}$ Because the outcomes of interest in this study, partisan differences in word classes, are very abstract it can be difficult to contextualize the findings presented in Table 6. Further exacerbating this problem is the fact that parts of speech are largely detached from the way political scientists typically think about language (i.e., in terms of content). I address this issue with exploratory analyses that build on the confirmatory results. Only tests of hypotheses included in the pre-registration can have the distinction of being confirmatory. In the context of this study, Table 6 encompass all of the confirmatory results. Alternatively, exploratory tests are not associated with specific hypotheses included in the pre-registration. In presenting my findings for each set of hypotheses (i.e., verb tense, pronoun number, and noun number) I first discuss results associated with confirmatory tests before moving into exploratory analyses.
} 


\subsection{Verb Tense}

Results from the confirmatory analyses for verb tense are displayed in the first two columns of Table 6 . I find support for both of my verb tense hypotheses (H1a and H1b). As anticipated, press releases from Republican senators are significantly more likely to use past tense verbs than those from Democrats. In contrast, the odds of a future tense verb being used are significantly higher in releases put out by Democrats than Republicans. The bottom rows of Table 6 show that, using more conservative priors for the intra-topic analyses, these differences are found to be significant in 19 and three topics, respectively. This suggests that while the use of past tense verbs by Republicans is fairly consistent across the corpus, a general balance in future tense verb use is punctuated by a few instances of Democratic dominance. This is discussed further below.

\subsubsection{Exploratory}

The confirmatory results suggest a relative propensity for Republicans to focus on the past and Democrats to draw attention to the future. They do not, however, provide any additional information about how the parties use those temporal frames - context that is important for assessing the validity of my findings. I address this issue with a series of exploratory analyses, which provide support for my theory linking party to temporal framing.

While both confirmatory verb tense findings are in line with my hypotheses (H1a and H1b) and statisti-

cally significant, the magnitude of $\zeta_{w}^{(R-D)}$ for past tense verbs (26.41) is nearly four times that of future tense verbs (-7.14). This difference in magnitudes is the result of a much larger estimated difference between the parties for past tense verbs $(O R=1.057$ vs. 0.973$)$ and a smaller variance around that estimate $(\sim 4.38 \mathrm{E}-6$ vs. $1.46 \mathrm{E}-5)$. A likely reason for this difference in the variance estimates is the relative rarity of future tense verb phrases. While past tense verbs appear over 900,000 times in the corpus, there are a few fewer than 300,000 instances of future tense verb phrases. That discrepancy aligns with intuition: past tense verbs are comprised of just one token, while future tense phrases are made up of two or three tokens. Further, past tense verbs take many forms, but the future tense verb phrase - as I have defined it - can only be formed in two ways. The phrase must have a modal (e.g., 'will') directly followed by either a base verb (e.g., 'be') or an adverb, base verb pair.

The difference in magnitudes of the $\zeta_{w}^{(R-D)}$ values is also reflected in the bottom rows of Table 6 . I find that Republicans are significantly more likely to use past tense verbs in 19 of the topics. Democrats, however, are significantly more likely to use verb phrases implying future actions in just three topics: "Nat'l Parks" (31), "Infrastructure" (32), and "Pork Spending" (35). A qualitative assessment of Democrats' press releases 
related to those three topics revealed that future tense verb phrases are often invoked while explaining the impacts of a bill or funding. For example, an excerpt of a press release from Senator Tom Udall (D-NM) in the "Nat'l Parks" topic discusses the implications of a conservation bill:

"The Organ Mountains-Desert Peaks Conservation Act provides permanent protection for some of Southern New Mexico's most scenic landscapes and will safeguard OMDP's sensitive cultural, historical and natural treasures for generations to come," (Udall 2016, emphasis added).

Additional analyses also revealed interesting differences in how the parties use future tense verb phrases. Across the full corpus, Democrats use the verb phrase "will help" more than twice as often as Republicans $(7,281$ vs 3,112$)$. This difference is also seen in other verb phrases concerning assistance. Republican press releases use the phrases "would help" and "will support" roughly half as often as Democratic pressers. Further exploration of future tense phrases across the entire corpus is consistent with those patterns. Table 7 shows the ten most partisan future tense verb phrases across all topics. The list of top Democratic phrases is almost entirely composed of verbs implying the future allocation of benefits: e.g., "will help", "will receive", "would help". This lends support to my expectation that Democrats focus on the future when discussing their government actions that will benefit constituents and groups.

Table 7: Most Partisan Future Verb Phrases in Corpus

(Uninformative Dirichlet Prior)

\begin{tabular}{lrr|llr}
\hline \multicolumn{2}{c|}{ Republican } & \multicolumn{3}{c}{ Democratic } \\
\hline lemma_TAG & $\zeta_{w}^{(R-D)}$ & Total Freq. & lemma_TAG & $\zeta_{w}^{(R-D)}$ & Total Freq. \\
\hline 'd_MD like_VB & 8.65 & 579 & will_MD help_VB & -26.10 & 10,393 \\
would_MD prevent_VB & 7.84 & 464 & will_MD receive_VB & -17.63 & 3,279 \\
will_MD have_VB & 7.50 & 2,682 & will_MD allow_VB & -15.33 & 2,994 \\
would_MD stop_VB & 6.97 & 133 & would_MD help_VB & -12.56 & 2,320 \\
can_MD tell_VB & 6.92 & 161 & will_MD use_VB & -12.30 & 871 \\
would_MD prohibit_VB & 6.71 & 430 & will_MD enable_VB & -9.51 & 818 \\
would_MD say_VB & 6.64 & 165 & can_MD continue_VB & -9.08 & 1,248 \\
would_MD note_VB & 6.50 & 76 & must_MD do_VB & -8.77 & 1,118 \\
'll_MD have_VB & 6.38 & 176 & can_MD access_VB & -8.70 & 334 \\
will_MD participate_VB & 6.17 & 177 & will_MD support_VB & -8.14 & 1,374 \\
\hline
\end{tabular}

Note: This list is based on a model where all other lemma-tag pairs are unigrams. This model is fit across all topics using an uninformative prior.

Interestingly, the left side of Table 7, displaying the top Republican phrases, includes six instances of the modal verb 'would'. This is in contrast to the one appearance in the Democratic list. What makes this interesting are the linguistic properties of that word: "Would is formally the past tense of will, and in its future-in-the-past meaning, the so-called conditional tense is clearly just the past counterpart of the future tense," (Binnick 2005, emphasis in original). That is to say, even in what I have classified as a future tense verb phrase, the majority of top Republican examples are not formally defined as "future tense". 
Based on the two word phrases shown in Table 7, it is hard to tell, in practice, how exactly senators are using 'would'. As such, I conducted a separate examination of 'would' that incorporated more contextual words. $^{34}$ This revealed that the most Democratic uses of 'would' are generally in reference to the future implications of some legislation, again consistent with my theory: e.g., "[which, that, bill] would help" and "act would [provide, give]". Although these types of phrases also appear in the most Republican list, a decidedly Republican use of 'would' treats it as an epistemic modal (i.e., immediate sense): "i would [note, encourage, say, like, ask]". Such a use of "would' does not imply the future and suggests that the partisan gap in verb tense may be greater than was measured in the confirmatory analyses.

Moving from differences across the corpus to the intra-topic analyses suggests that the partisan divide in temporal framing is especially pronounced in particular topics. Figure 2 shows the most partisan past and future tense verbs in documents assigned to the "Immigration" topic. A couple of patterns are revealed in this graphic. First, the relative ratio of past to future tense verbs is heavily skewed by party. Of the 15 top past/future tense verbs associated with the Republican Party, 14 are past tense. For the Democratic Party, that count drops to $9 .{ }^{35}$ Second, there is a striking difference in the content of these verbs between the parties. While the top Republican verbs seem to imply the criminality of immigrants or punishment thereof (e.g., 'convicted', 'arrested', 'killed', 'held', 'sent', 'forced'), Democratic verbs tend to focus on assistance ('[will, would] help', 'awarded', 'earned', 'helped', 'will [support, enable]', 'funded', 'would create', 'can access'). This pattern in substance is also visible when examining the future action verb phrases in Table 7.

The confirmatory and exploratory analyses suggest that there are differences in the parties' propensities to use past and future tense verbs. Those differences align with my expectations that Republicans are more likely to use past tense verbs and Democrats are more likely to use the future tense. Exploratory analyses also point to interesting linguistic and semantic differences in how the parties use those verb tenses. Even when Republicans use what I have defined as "future tense verb phrases", they tend to do so in a way that is oriented to the present (i.e., epistemic) and not the future (or future in the past). Finally, the parties also differ in the content associated with their verbs that is consistent with the asymmetric parties argument put forth by Grossmann and Hopkins (2016). Across the corpus and within individual topics, Democrats tend to use past and future tense verbs to discuss bringing benefits to particular social groups. Alternatively, Republicans appear to use these tenses when talking about preventing or stopping something. ${ }^{36}$

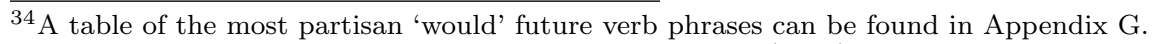

${ }^{35}$ Indeed the estimate on past tense verbs in this topic is $\zeta_{k w}^{(R-D)}=6.28$.

${ }^{36}$ This divergence can also be seen in the analysis of a "Tax" topic by (Monroe, Colaresi and Quinn, 2008, 392-393).
} 
Figure 2: Partisan Past \& Future Tense Verbs - Immigration (Informative Dirichlet Prior)

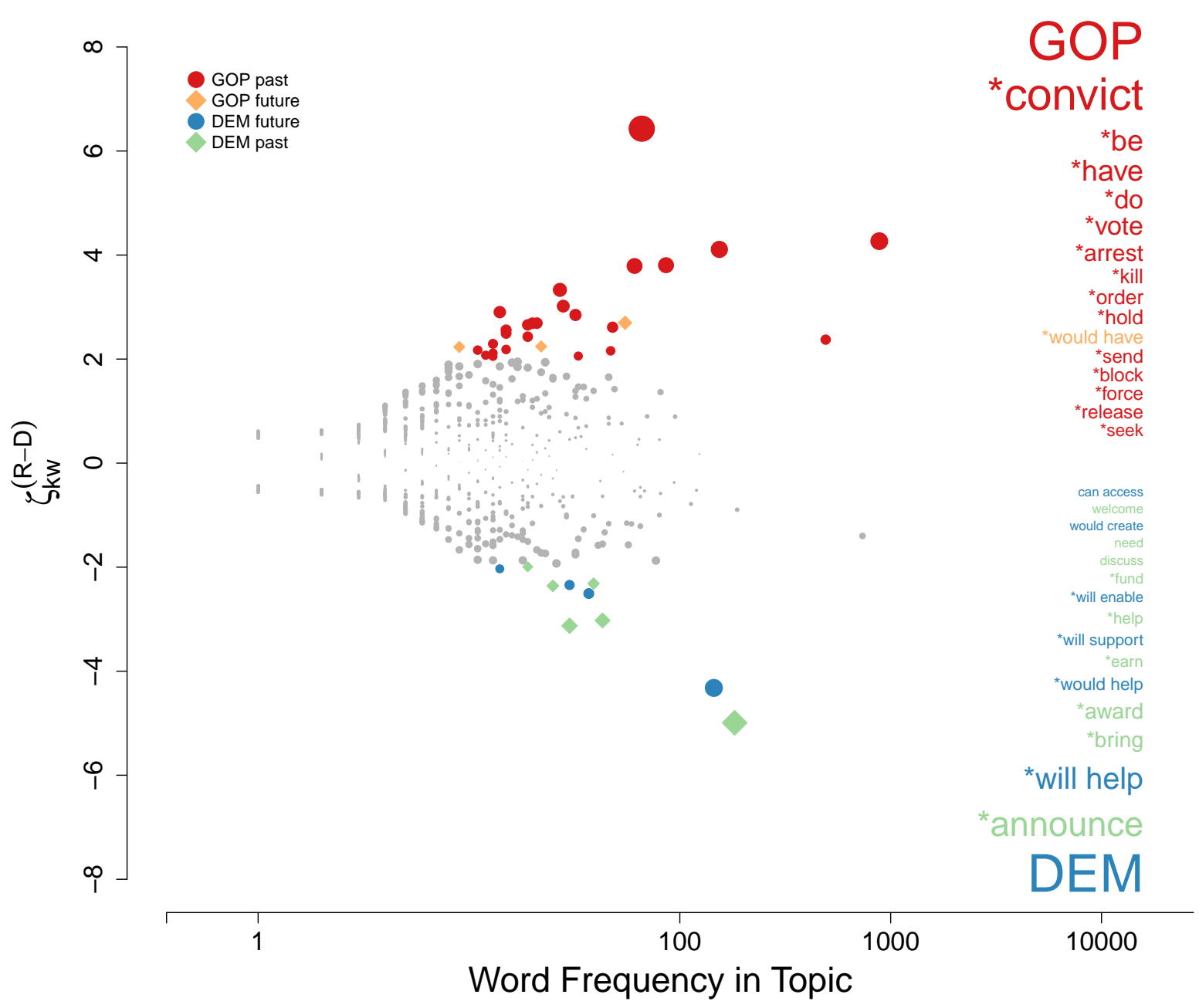

Note: Words with an $\left|\zeta_{k w}^{(R-D)}\right| \geq 1.96$ are the colored points, while other words have a gray fill. Red circles and orange diamonds indicate past and future tense verbs that are associated with Republican press releases. Blue circles and green diamonds represent future and past tense verbs associated with Democratic releases. The 15 past/future tense verb lemmas most strongly associated with each party are listed on the right. Those eclipsing the critical value are starred. The size and spacing of the list text correspond to the lemmas' respective zeta values. This is an exploratory analysis based on a mild variant of the unigram model. 


\subsection{Pronouns}

As expected, the partisan differences in grammar are not limited to verb tense. Consistent with my pronoun number hypotheses (H2a and $\mathrm{H} 2 \mathrm{~b})$, the results indicate that while Republicans are more likely to use

singular pronouns $\left(\zeta_{w}^{(R-D)}=69.62\right)$, plural pronouns are associated with Democrats $\left(\zeta_{w}^{(R-D)}=-10.22\right)$. The relationship between Republicans and singular pronouns is especially pronounced. In each of the 45 topics Republicans are more likely to use singular pronouns than their Democratic colleagues, and in 42 of those topics that difference is statistically significant. ${ }^{37}$ Across the full corpus, the odds of singular pronoun being used instead of another POS are estimated to be over $26 \%$ higher for Republican press releases.

\subsubsection{Exploratory}

The confirmatory results point toward a Republican Party that is more likely to highlight individuals and a Democratic Party with a relatively increased tendency to frame the discussion in terms of groups. The manifestation of this partisan difference in pronoun number can only be seen in exploratory analyses, though. The most basic of these examines the most partisan pronouns in the corpus. Pronoun lemmas most strongly associated with Republicans and Democrats are listed in Table 8. The general findings from the confirmatory tests remain visible in this table: the four most Republican pronouns are singular, while three of the top five most Democratic pronouns are plural. ${ }^{38}$

Table 8: Most Partisan Pronouns in Corpus

(Uninformative Dirichlet Prior)

\begin{tabular}{llrr}
\hline & lemma_TAG & $\zeta_{w}^{(R-D)}$ & Total Freq. \\
\hline Republicans & & & \\
& it_PRPSING & 44.76 & 106,547 \\
& his_PRPSING & 35.79 & 33,348 \\
& he_PRPSING & 35.29 & 27,913 \\
& i_PRPSING & 29.51 & 100,393 \\
& you_PRP & 23.95 & 33,472 \\
& & & \\
& they_PRPPLUR & -2.66 & 60,416 \\
& she_PRPSING & -3.57 & 9,460 \\
& themselves_PRPPLUR & -6.02 & 2,603 \\
& her_PRPSING & -8.62 & 13,493 \\
& their_PRPPLUR & -26.58 & 84,373 \\
\hline
\end{tabular}

Note: This list is based on the unigram model fit across all topics and constitutes an exploratory result. The lemma 'you' is not classified as either singular or plural given its number ambiguity.

Even after delineating singular and plural pronouns by their lemma, it can still be difficult to understand

${ }^{37}$ The three outlier topics are "Guns" (4), "Student Loans" (39), and "Children" (41).
${ }^{38}$ The lemma "you' is not classified as either singular or plural given its ambiguity. 
the substantive differences in pronoun use from Table 8. By examining pronouns in the context of the surrounding words, those differences become more easily apparent. In Figure 3, I show the most partisan bigrams and trigrams that contain a pronoun. This graphic is based on counts observed across all topics in the corpus. ${ }^{39}$ By including the contextual language in the pronoun analysis, some substantively interesting relationships are illuminated. First, although Democrats are more likely, overall, to use plural pronouns, markedly Republican uses of plural pronouns tend to be tied to the military ("our [troops, military, allies]"). Though not shown in the figure, this pattern continues further into the list of Republican phrases: "our [veterans, enemies, men, men and, national security]" also appear in the 50 most Republican pronoun phrases. In that same set of phrases, plural pronouns are only used four times without explicit reference to the military or defense: "what we", "we have", "our debt", "our nation".

Second, the phrases most strongly associated with Democrats highlight an allocation of resources - the same pattern that emerged in the exploratory analyses of verb tense. A number of those phrases in the Democratic list appear to be used together frequently ("they need [to]", "do their [jobs]", "resources they [need]") and can be read to form a longer phrase: "the resources they need to do their jobs". The 50 most Democratic pronoun phrases include more references to resources and their recipients: "our [first responders, local, firefighters, families, community]", "equipment they [need]", "[to] help them". This lends support to the argument that the Democratic Party is composed of policy seeking groups (Grossmann and Hopkins 2016).

\subsection{Noun Number}

Finally, the two rightmost columns of Table 6 present results from the noun number analyses. I am not able to reject the null hypothesis that there is a significant difference in the use of singular nouns by Republicans and Democrats $\left(\zeta_{w}^{(R-D)}=2.50\right)$. While the test statistic is correctly signed - i.e., Republican press releases are more likely to use singular nouns $(\mathrm{H} 3 \mathrm{~b})$ - it is of insufficient magnitude to be considered significant. Alternatively, I find that Democrats are significantly more likely to use plural nouns across all topics $\left(\zeta_{w}^{(R-D)}=-68.51\right)$, which is congruent with my hypothesis (H3a). This finding holds remarkably well in the intra-topic analyses. In every individual topic the relationship is correctly signed and achieves significance in 41 of 45 topics.

Both of the noun number results displayed in Table 6 are, however, based on the broad singular and plural noun classes, which obscure lower-level variation within and between the parties. As I show in the exploratory results for noun number, the patterns seen here are largely due to the aggregation of multiple

\footnotetext{
${ }^{39}$ Unlike other exploratory analyses, these results are not based on the unigram model. In other words, the total word counts for each party that are fed into the model are based on counts of unigrams, bigrams, and trigrams.
} 
Figure 3: Partisan Pronoun Bi- \& Trigram Lemmas in Corpus (Uninformative Dirichlet Prior)

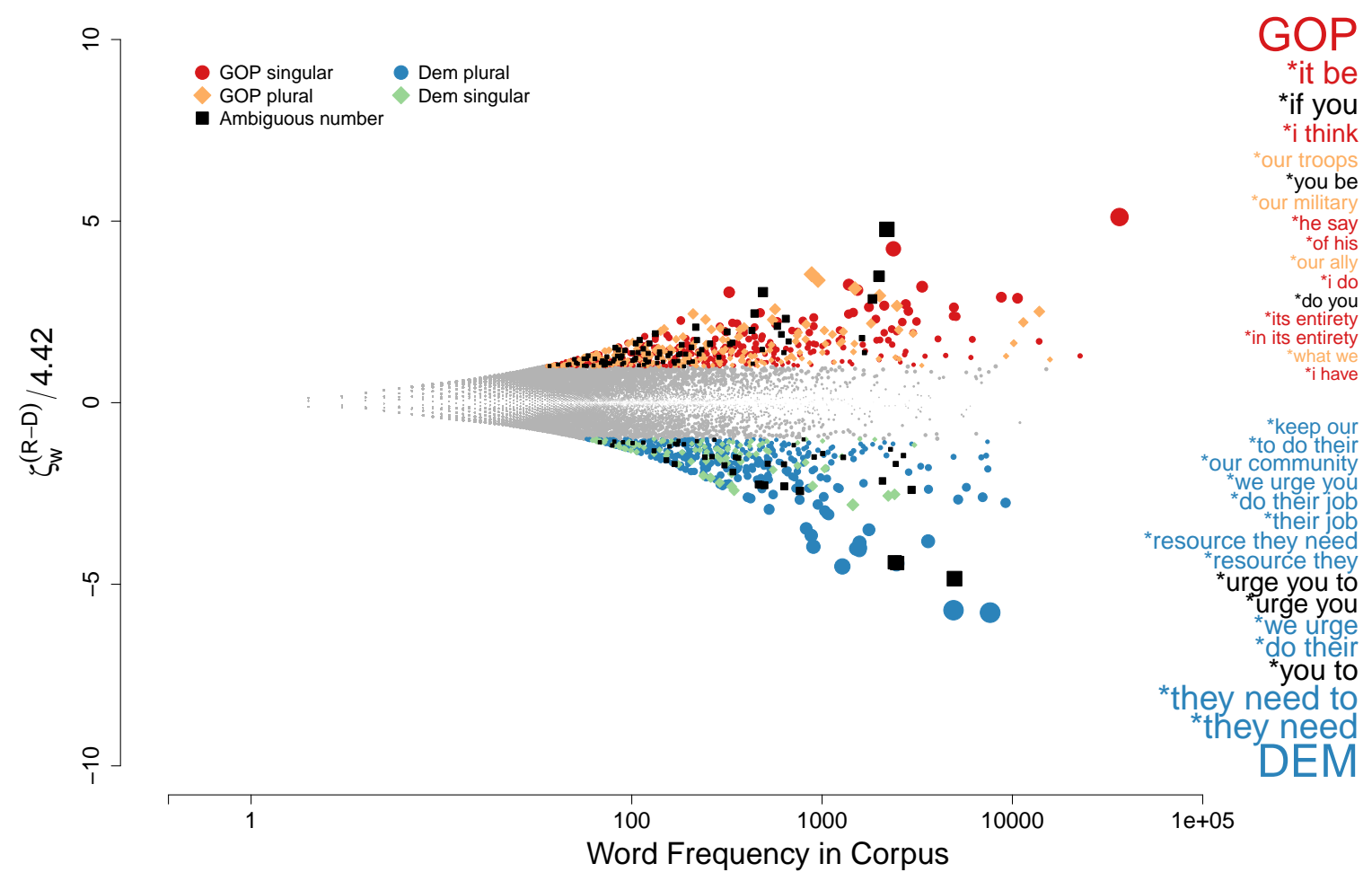

Note: The y-axis represents $\zeta_{w}^{(R-D)}$ values that have been scaled by the inter-topic significance threshold (4.42). Bi- and trigrams with an $\left|\zeta_{w}^{(R-D)}\right| \geq 4.42$ are the colored points, while other pronoun phrases have a gray fill. Red circles and orange diamonds indicate singular and plural pronoun ngrams that are associated with Republican press releases. Blue circles and green diamonds represent plural and singular pronoun ngrams associated with Democratic releases. Black squares are used for ngrams containing a pronoun of ambiguous number (e.g., 'you'); the partisanship of these ngrams is indicated by their placement on the y-axis. The 15 pronoun ngram lemmas most strongly associated with each party are listed on the right. Those eclipsing the critical value are starred. The size and spacing of the list text correspond to the lemmas' respective zeta values. This figure is based on the full model and is an exploratory analysis. ${ }^{a}$

${ }^{a}$ Although the counts and $\zeta_{w}^{(R-D)}$ values were calculated using all uni-,bi-, and trigrams in the corpus, not all pronoun bi- and trigrams are included in this figure. Due to the sheer volume of those ngrams (roughly $581 \mathrm{~K})$, they were sampled with $\operatorname{Pr}(\mathrm{keep})=\max \left(\log \left(y_{w}\right) / 3,1\right)$. Summary statistics of the omitted pronoun ngrams indicate that none of the omitted ngrams were significantly associated with either party and all appeared 19 or fewer times in the entire corpus. 
word classes. The true relationship between noun number and partisanship is more complicated than the confirmatory results presented in Table 6 suggest.

\subsubsection{Exploratory}

As noted earlier, partisan differences in word classes, especially ones as broad as singular and plural nouns, are very abstract. Like with the previous results, it can be helpful to deconstruct those classes into semantically meaningful units and then do an exploratory analysis of differences with those new units. I do this in Table 9 by identifying the 15 most partisan nouns in the corpus, excluding proper nouns. ${ }^{40}$ The nouns most strongly associated with Republicans appear in the left side of the table, with the Democratic equivalent on the right.

Table 9: Most Partisan Nouns in Corpus (Excluding Proper Nouns)

\begin{tabular}{lrr|lrr}
\hline \multicolumn{2}{c}{ Republican } & & \multicolumn{3}{c}{ Democratic } \\
\hline lemma_TAG & $\zeta_{w}^{(R-D)}$ & Total Freq. & lemma_TAG & $\zeta_{w}^{(R-D)}$ & Total Freq. \\
\hline administration_NN & 59.12 & 12,065 & funding_NN & -59.52 & 35,040 \\
chairman_NN & 48.90 & 5,509 & student_NNS & -43.99 & 18,692 \\
president_NN & 47.99 & 6,927 & community_NNS & -41.90 & 21,694 \\
it_PRPSING & 44.76 & 106,547 & safety_NN & -40.39 & 14,675 \\
rule_NN & 37.17 & 9,270 & grant_NN & -34.73 & 9,326 \\
his_PRPSING & 35.79 & 33,348 & consumer_NNS & -32.52 & 7,512 \\
he_PRPSING & 35.29 & 27,913 & family_NNS & -32.19 & 24,092 \\
regulation_NNS & 34.88 & 6,377 & housing_NN & -31.96 & 5,885 \\
government_NN & 33.67 & 23,100 & firefighter_NNS & -31.26 & 2,853 \\
terrorist_NNS & 31.51 & 3,245 & company_NNS & -31.12 & 9,957 \\
deal_NN & 31.23 & 6,462 & resource_NNS & -30.93 & 14,602 \\
statement_NN & 29.71 & 13,176 & fire_NN & -30.45 & 4,542 \\
detainee_NNS & 29.57 & 1,579 & investment_NNS & -30.41 & 4,294 \\
i_PRPSING & 29.51 & 100,393 & community_NN & -30.23 & 15,344 \\
freedom_NN & 29.43 & 3,500 & climate_NN & -30.06 & 4,336 \\
\hline
\end{tabular}

\footnotetext{
Note: This list is based on the unigram model fit across all topics and is exploratory. Proper nouns are excluded from the table because they are generally uninformative; the most partisan proper nouns are Senators' names and states, which appear as part of a boilerplate introduction in nearly all of the press releases.
}

Both lists contain a substantial number of singular nouns, but plural nouns make up just three of the Republican entries; the Democratic side of the table contains eight. That difference is made more prominent by the content of the plural nouns occupying each list. When using plural nouns, Democrats are much more likely to do so in reference to specific constituencies and resources for them: 'students', 'communities', 'consumers', 'families', 'firefighters', 'resources', 'investments'. This is in stark contrast to the use of plural nouns by Republicans: 'regulations', 'terrorists', 'detainees'. Another notable feature of Table 9 is the

\footnotetext{
${ }^{40}$ Recall that the category of noun is defined here as encapsulating pronouns, nouns, and proper nouns.
} 
prevalence(absence) of pronouns in each list. The four most Republican pronouns (Table 8) are also included in the list of most Republican (non-proper) nouns. Conversely, the Democratic list does not contain any examples of pronouns. ${ }^{41}$

Such a pronounced difference in the ratio of pronouns suggests that the broad noun classes (including nouns, pronouns, and proper nouns) may be veiling more complex, lower level variation. In other words, results of the noun number confirmatory analyses may be due to the aggregation of multiple word classes. I evaluate this possibility by exploring partisan differences across the corpus for each individual word class that contributes to the noun super-class. The results of this can be seen in Table 10 .

Table 10 reveals that the tags contributing to each noun super-class are not all aligned with one another. Although the plural noun superclass was positively and significantly associated with the Democratic Party as expected, this is not true of all the plural subclasses. Plural pronouns (PRPPLUR) and nouns (NNS) were both more likely to be used in Democratic press releases, but Republicans were more likely to use plural proper nouns (NNPS). Based on the enormous magnitude of its $\zeta_{w}^{(R-D)}$ value, the observed relationship between Democrats and the plural noun superclass appears to be driven primarily by the NNS tag - and in spite of the tendency for Republicans to use plural proper nouns. Conversely, the (statistically insignificant) relationship between Republicans and the singular noun superclass is due entirely to the use of singular pronouns (PRPSING) - despite their rarity relative to the other tags. Unexpectedly, the singular noun (NN) and proper noun (NNP) component word classes were both strongly associated with Democratic press releases, across topics.

Table 10: Partisan Alignment of Noun Subclasses in Corpus (Uninformative Dirichlet)

\begin{tabular}{llrr}
\hline & Word Class (TAG) & $\zeta_{w}^{(R-D)}$ & Total Freq. \\
\hline \multirow{4}{*}{ Singular } & Pronoun (PRPSING) & 69.62 & 360,293 \\
& Noun (NN) & -11.04 & $3,342,653$ \\
& Proper Noun (NNP) & -9.07 & $3,523,920$ \\
Plural & Pronoun (PRPPLUR) & -9.83 & 442,050 \\
& Noun (NNS) & -75.61 & $1,591,104$ \\
& Proper Noun (NNPS) & 8.92 & 107,108 \\
\hline
\end{tabular}

Note: This table is based on the ngram model fit across all topics using an uninformative prior.

\footnotetext{
$\overline{{ }^{41} \text { The first instance of a pronoun in the Democratic }}$ list is at the $31^{\text {st }}$ spot ('their_PRPPLUR').
} 


\section{Discussion and Conclusion}

Although it has been previously shown that political identity is related to the language people use (e.g., Monroe, Colaresi and Quinn 2008), this study provides novel evidence that political identity is not just related to what people say, but also how they say it. Using text annotation methods to link stylistic frames with their linguistic manifestations and an original collection of senate press releases, I find evidence of partisan differences in the use of temporal and subject-scope stylistic frames. Further, the results indicate these differences are in line with theoretical expectations based on party type (e.g., Freeman 1986; Grossmann and Hopkins 2016; Nexon 1971) and the parties' respective positions regarding novelty and individualism (e.g., Carney et al. 2008; Jost, Federico and Napier 2009; Lelkes and Sniderman 2016).

I find that press releases from Republicans are more likely to use past tense verbs than those from Democrats, thereby framing their releases around what has been done, but Democratic releases are more likely to use future tense verb phrases, instead highlight what will be done. This is the first study to show that there are partisan, not just ideological, differences in the use of past and future tenses, and that these differences are exhibited by political elites (see, Robinson et al. 2015). As shown in the exploratory analyses, this framing is not done independently of content, and is often used to accentuate content frames. This is especially intriguing given recent evidence of fundamental differences between the parties (Grossmann and Hopkins 2016).

The results also present the first evidence that the parties differ in their use of subject-scope framing. Measured with the linguistic feature of pronoun number, Democratic press releases are found to be more likely to focus on groups and the collective. Alternatively, Republican press releases are more likely to focus on individual people or entities - particularly the "authoring" senator. Subject-scope frames are also found to be used in conjunction with content frames. The highly skewed use of singular personal pronouns in Republican releases can broadly be seen as the senators advertising their own conservative purity (e.g., "I [think, do, have]"), and the plural personal pronoun phrases that are most strongly aligned with the Republican Party focus attention on national defense (e.g., "our [troops, military, allies]"). On the other hand, Democratic press releases tend to use plural pronouns in phrases addressing the needs of, and resources being provided to, groups.

Trends in subject-scope framing found with pronouns do not appear to extend to all nouns, however. While Democrats are more likely to use plural common nouns, they are also more likely to use singular common nouns. And in complete opposition to expectations, plural proper nouns are associated with Republican press releases, but singular proper nouns are more likely to appear in Democrats' releases. One potential explanation for this finding is that Democratic politicians are more likely to use all number of common nouns 
in communications with constituents because even singular nouns correspond to the provision of benefits (e.g., 'funding', 'grant', 'housing'), and that Republicans are more likely to use plural pronouns as a means of creating "order" of complex groups (Cichocka et al. 2016; Jost et al. 2003).

The link between partisanship and style is by no means absolute and the results show that in particular contexts partisans may "co-opt" a style generally associated with the other party (e.g., the distinctly Republican use of 'our' when discussing the military and defense). Thus, further investigation is needed into the conditions under which styles are pronounced or muted. For example, does stylistic framing depend on representative-constituent alignment, like an emphasis on pork or policy (Grimmer 2013b), or proximity to the election, which Kim, Rao and Lee (2009) suggest could be important.

Like most research involving text as data, this study is limited by a number of factors. First, it is observational in nature. As such, potential causal pathways describing the relationships found between partisan identity and linguistic style cannot be tested. Additionally, there is an increased risk for the findings to be the result of one or more unmeasured, confounding variables. Second, I only have press releases for all active senators during the $114^{\text {th }}$ Congress. In previous Congresses I only have releases from senators who remained in the Senate through the $114^{\text {th }}$. Power in the Senate might moderate the relationship between partisanship and style, but I do not have the data to assess this possibility. This study is also limited in how generalizable it is. U.S. Senators constitute a very particular group of individuals, and while the findings may be valid for that population, there is a distinct possibility that they do not hold for others. Finally, there is a limitation in measurement. Language is complex and measuring it is difficult, especially at scale. There is, no doubt, measurement error in this study. And while I have done my best to find and remedy it, there is no guarantee that it is not affecting the results.

Acknowledging those limitations, the findings of this study have implications for a number of research topics. While previous research on political framing has focused almost exclusively on the role of content, I demonstrate that linguistic style also plays an important part and that, like content, the style employed by an author or speaker is related to that person's social identity. This study indicates that political identities, like partisanship, may have a deeper role in cognitive style and language than has been previously noted. The evidence presented in this study also suggests a number of similarities between style and content frames. They appear to complement one another and are often used together to draw attention toward a particular aspect of the discussion. Their use also differs based on traits of the author/speaker (e.g., partisanship). Whether the similarities stop there or not remains to be seen. 


\section{References Cited}

Alexander, Jeffrey C. 2008. The Civil Sphere. Oxford University Press.

Alexander, Sen. Lamar. 2016. "Alexander: FDAs Proposed Double Regulation Could Halt More Than 60,000 Lab-developed Tests Americans Depend on for Lifesaving Treatments, Cures." Press Release. Accessed November 16, 2017.

URL: https://www.alexander.senate.gov/

Associated Press. 2017. The Associated Press Stylebook. New York: Associated Press.

Athanasopoulos, Panos. 2006. "Effects of the grammatical representation of number on cognition in bilinguals." Bilingualism: Language and Cognition 9(1):89-96.

Baldwin, Matthew and Joris Lammers. 2016. "Past-focused environmental comparisons promote proenvironmental outcomes for conservatives." Proceedings of the National Academy of Sciences 113(52):14953-14957.

Barbaranelli, Claudio, Gian Vittorio Caprara, Michele Vecchione and Chris R Fraley. 2007. "Voters personality traits in presidential elections." Personality and Individual Differences 42(7):1199-1208.

Baumer, Eric, Elisha Elovic, Ying Qin, Francesca Polletta and Geri Gay. 2015. Testing and comparing computational approaches for identifying the language of framing in political news. In Proceedings of the 2015 Conference of the North American Chapter of the Association for Computational Linguistics: Human Language Technologies. pp. 1472-1482.

Baumgartner, Frank R, Suzanna L De Boef and Amber E Boydstun. 2008. The decline of the death penalty and the discovery of innocence. Cambridge University Press.

Binnick, Robert I. 2005. "The markers of habitual aspect in English." Journal of English Linguistics 33(4):339-369.

Bird, Steven, Ewan Klein and Edward Loper. 2009. Natural Language Processing with Python. 1st ed. O'Reilly Media, Inc.

Blei, David M, Andrew Y Ng and Michael I Jordan. 2003. "Latent dirichlet allocation." Journal of machine Learning research 3(Jan):993-1022.

Blei, David M and John D Lafferty. 2006. Dynamic topic models. In Proceedings of the 23rd International Conference on Machine learning. ACM pp. 113-120.

Blei, David M and Michael I Jordan. 2006. "Variational inference for Dirichlet process mixtures." Bayesian Analysis 1(1):121-143.

URL: https://doi.org/10.1214/06-BA104

Brysbaert, Marc, Michaël Stevens, Paweł Mandera and Emmanuel Keuleers. 2016. "How many words do we know? Practical estimates of vocabulary size dependent on word definition, the degree of language input and the participants age." Frontiers in psychology 7:1116.

Bussmann, Hadumod. 2006. Routledge Dictionary of Language and Linguistics. New York: Taylor \& Francis e-Library. Translated by Gregory P Trauth and Kerstin Kazzazi.

Cacciatore, Michael A, Dietram A Scheufele and Shanto Iyengar. 2016. "The end of framing as we know it and the future of media effects." Mass Communication and Society 19(1):7-23.

Campbell, R Sherlock and James W Pennebaker. 2003. "The secret life of pronouns: Flexibility in writing style and physical health." Psychological science 14(1):60-65.

Card, Dallas, Amber E Boydstun, Justin H Gross, Philip Resnik and Noah A Smith. 2015. The Media Frames Corpus: Annotations of Frames Across Issues. In ACL (2). pp. 438-444. 
Carney, Dana R, John T Jost, Samuel D Gosling and Jeff Potter. 2008. "The secret lives of liberals and conservatives: Personality profiles, interaction styles, and the things they leave behind." Political Psychology $29(6): 807-840$.

Chong, Dennis and James N. Druckman. 2007. "Framing Public Opinion in Competitive Democracies." The American Political Science Review 101(4):637-655.

Cichocka, Aleksandra, Micha Bilewicz, John T Jost, Natasza Marrouch and Marta Witkowska. 2016. "On the Grammar of Politics-or Why Conservatives Prefer Nouns." Political Psychology 37(6):799-815.

URL: $h t t p: / /$ dx.doi.org/10.1111/pops.12327

Clark, Kevin and Christopher D. Manning. 2016. Deep Reinforcement Learning for Mention-Ranking Coreference Models. In Empirical Methods on Natural Language Processing.

URL: https://nlp.stanford.edu/pubs/clark2016deep.pdf

Contract with America. 1994.

URL: https://web.archive.org/web/19990427174200/http://www.house.gov/house/Contract/CONTRACT.html

Cooper, Christopher A, Lauren Golden and Alan Socha. 2012. "The Big Five Personality Factors and Mass Politics." Journal of Applied Social Psychology 43(1):68-82.

Denny, Matthew J. and Arthur Spirling. 2018. "Text Preprocessing For Unsupervised Learning: Why It Matters, When It Misleads, And What To Do About It." Political Analysis p. 122.

Dietrich, Bryce J, Ryan D Enos and Maya Sen. 2018. "Emotional Arousal Predicts Voting on the U.S. Supreme Court." Political Analysis . Forthcoming.

Dietrich, Bryce J, Scott Lasley, Jeffery J Mondak, Megan L Remmel and Joel Turner. 2012. "Personality and Legislative Politics: The Big Five Trait Dimensions Among U.S. State Legislators." Political Psychology 33(2):195-210.

Fausey, Caitlin M and Teenie Matlock. 2011. "Can Grammar Win Elections?" Political Psychology 32(4):563574 .

Feldman, Stanley and John Zaller. 1992. "The political culture of ambivalence: Ideological responses to the welfare state." American Journal of Political Science pp. 268-307.

Fenno, Richard F. 1978. Home style: House members in their districts. Little, Brown and Company.

Fong, Christian and Justin Grimmer. 2016. Discovery of Treatments from Text Corpora. In Proceedings of the Annual Meeting of the Association for Computational Linguistics.

Freeman, Jo. 1986. "The Political Culture of the Democratic and Republican Parties." Political Science Quarterly 101(3):327-356.

Gentzkow, Matthew and Jesse M Shapiro. 2010. "What drives media slant? Evidence from US daily newspapers." Econometrica 78(1):35-71.

Gerber, Alan S, Gregory A Huber, David Doherty and Conor M Dowling. 2011. "The big five personality traits in the political arena." Annual Review of Political Science 14:265-287.

Gerber, Alan S, Gregory A Huber, David Doherty and Conor M Dowling. 2012. "Personality and the Strength and Direction of Partisan Identification." Political Behavior 34(4):653-688.

Gill, Alastair J, Scott Nowson and Jon Oberlander. 2009. What Are They Blogging About? Personality, Topic and Motivation in Blogs. In Proceedings of the Third International Conference on Web and Social Media. AAAI pp. 18-25.

Golbeck, Jennifer, Cristina Robles, Michon Edmondson and Karen Turner. 2011. Predicting personality from twitter. In 2011 IEEE Third International Conference on Privacy, Security, Risk and Trust (PASSAT), and IEEE International Conference on Social Computing. IEEE pp. 149-156. 
Greene, Derek and James P Cross. 2017. "Exploring the Political Agenda of the European Parliament Using a Dynamic Topic Modeling Approach." Political Analysis pp. 77-94.

Grimmer, Justin. 2010. "A Bayesian Hierarchical Topic Model for Political Texts: Measuring Expressed Agendas in Senate Press Releases." Political Analysis 18(1):1-35.

Grimmer, Justin. 2013a. "Appropriators not position takers: The distorting effects of electoral incentives on congressional representation." American Journal of Political Science 57(3):624-642.

Grimmer, Justin. 2013b. Representational Style in Congress: What Legislators Say and Why It Matters. Cambridge University Press.

Grimmer, Justin and Brandon M. Stewart. 2013. "Text as Data: The Promise and Pitfalls of Automatic Content Analysis Methods for Political Texts." Political Analysis 21(3):267-297.

Grose, Christian R, Neil Malhotra and Robert Parks Van Houweling. 2015. "Explaining explanations: How legislators explain their policy positions and how citizens react." American Journal of Political Science $59(3): 724-743$.

Grossmann, Matt and David Hopkins. 2016. Asymmetric Politics. Oxford, United Kingdom: Oxford University Press.

Huang, Zhiheng, Wei Xu and Kai Yu. 2015. "Bidirectional LSTM-CRF models for sequence tagging." arXiv preprint arXiv:1508.01991.

Iyengar, Shanto. 1990. "Framing responsibility for political issues: The case of poverty." Political Behavior $12(1): 19-40$.

Iyengar, Shanto, Mark D Peters and Donald R Kinder. 1982. "Experimental demonstrations of the not-sominimal consequences of television news programs." American Political Science Review 76(4):848-858.

Jensen, Jacob, Suresh Naidu, Ethan Kaplan, Laurence Wilse-Samson, David Gergen, Michael Zuckerman and Arthur Spirling. 2012. "Political polarization and the dynamics of political language: Evidence from 130 years of partisan speech [with comments and discussion]." Brookings Papers on Economic Activity pp. $1-81$.

Jordan, Michael I, Zoubin Ghahramani, Tommi S Jaakkola and Lawrence K Saul. 1999. "An introduction to variational methods for graphical models." Machine learning 37(2):183-233.

Jost, John T. 2006. "The end of the end of ideology." American Psychologist 61(7):651.

Jost, John T, Christopher M Federico and Jaime L Napier. 2009. "Political ideology: Its structure, functions, and elective affinities." Annual review of psychology 60:307-337.

Jost, John T., Jack Glaser, Arie W Kruglanski and Frank J Sulloway. 2003. "Political conservatism as motivated social cognition." Psychological bulletin 129(3):339-375.

Kim, Hakkyun, Akshay R. Rao and Angela Y. Lee. 2009. "It's Time to Vote: The Effect of Matching Message Orientation and Temporal Frame on Political Persuasion." Journal of Consumer Research 35(6):877-889.

Kiss, Tibor and Jan Strunk. 2006. "Unsupervised Multilingual Sentence Boundary Detection." Computational Linguistics 32(4):485-525.

URL: http://dx.doi.org/10.1162/coli.2006.32.4.485

Lakoff, George. 2010. "Why it matters how we frame the environment." Environmental Communication $4(1): 70-81$.

Lammers, Joris and Matt Baldwin. 2018. "Past-focused temporal communication overcomes conservatives resistance to liberal political ideas." Journal of personality and social psychology 114(4):599-619. 
Laver, Michael, Kenneth Benoit and John Garry. 2003. "Extracting policy positions from political texts using words as data." American Political Science Review 97(02):311-331.

Lee, Daniel D and H Sebastian Seung. 1999. "Learning the parts of objects by non-negative matrix factorization." Nature 401(6755):788-791.

Lelkes, Yphtach and Paul M Sniderman. 2016. "The ideological asymmetry of the American party system." British Journal of Political Science 46(4):825-844.

Lipinski, Daniel. 2004. Congressional communication: Content and consequences. University of Michigan Press.

Manning, Christopher D. 2011. Part-of-speech tagging from $97 \%$ to 100\%: is it time for some linguistics? In International Conference on Intelligent Text Processing and Computational Linguistics. Springer pp. 171189.

Manning, Christopher D and Hinrich Schütze. 1999. Foundations of statistical natural language processing. MIT Press.

Marcus, Mitchell P, Mary Ann Marcinkiewicz and Beatrice Santorini. 1993. "Building a large annotated corpus of English: The Penn Treebank." Computational Linguistics 19(2):313-330.

Mayhew, David R. 1974. Congress: The electoral connection. Yale University Press.

Mehl, Matthias R, Samuel D Gosling and James W Pennebaker. 2006. "Personality in its natural habitat: manifestations and implicit folk theories of personality in daily life." Journal of personality and social psychology 90(5):862.

Minnen, Guido, John Carroll and Darren Pearce. 2001. "Applied morphological processing of English." Natural Language Engineering 7(3):207-223.

Mondak, Jeffery J. 2010. Personality and the foundations of political behavior. Cambridge University Press.

Mondak, Jeffery J and Karen D Halperin. 2008. "A framework for the study of personality and political behaviour." British Journal of Political Science 38(2):335-362.

Monroe, Burt L, Michael P Colaresi and Kevin M Quinn. 2008. "Fightin' words: Lexical feature selection and evaluation for identifying the content of political conflict." Political Analysis pp. 372-403.

Nelson, Thomas E, Rosalee A Clawson and Zoe M Oxley. 1997. "Media Framing of a Civil Liberties Conflict and Its Effect on Tolerance." American Political Science Review 91(3):567583.

Newman, Matthew L, James W Pennebaker, Diane S Berry and Jane M Richards. 2003. "Lying words: Predicting deception from linguistic styles." Personality and social psychology bulletin 29(5):665-675.

Nexon, David. 1971. "Asymmetry in the Political System: Occasional Activists in the Republican and Democratic Parties, 1956-1964." The American Political Science Review 65(3):716-730.

Nicholson, Stephen P and Robert M Howard. 2003. "Framing Support for the Supreme Court in the Aftermath of Bush v. Gore." Journal of Politics 65(3):676-695.

Obama, Barack. 2008. "The American Promise.". Delivered on August 28 at the Democratic National Convention in Denver, Colorado.

URL: https://www.npr.org/templates/story/story.php?storyId $=94087570$

Paatero, Pentti and Unto Tapper. 1994. "Positive matrix factorization: A non-negative factor model with optimal utilization of error estimates of data values." Environmetrics 5(2):111-126.

Parker, Ashley. 2016. "In 'Good Old Days,' Donald Trump Says, Campaign Protestors Got More Than Just an Escort Out." The New York Times . Accessed April 11, 2017.

URL: $\quad$ https://www.nytimes.com/politics/first-draft/2016/02/27/in-good-old-days-donald-trump-sayscampaign-protesters-got-more-than-just-an-escort-out/ 
Pedersen, Rasmus T. 2017. "Ratio Bias and Policy Preferences: How Equivalency Framing of Numbers Can Affect Attitudes." Political Psychology 38(6):1103-1120.

Pedregosa, F., G. Varoquaux, A. Gramfort, V. Michel, B. Thirion, O. Grisel, M. Blondel, P. Prettenhofer, R. Weiss, V. Dubourg, J. Vanderplas, A. Passos, D. Cournapeau, M. Brucher, M. Perrot and E. Duchesnay. 2011. "Scikit-learn: Machine Learning in Python." Journal of Machine Learning Research 12:2825-2830.

Pennebaker, James W. 2011. The secret life of pronouns: How our words reflect who we are. Bloomsbury.

Pennebaker, James W. 2013. "How authors' forgettable words reveal their personality and social behaviors." Information Design Journal (IDJ) 20(3):267-272.

Pérez, Efrén O. and Margit Tavits. 2017. "Language Shapes People's Time Perspective and Support for Future-Oriented Policies." American Journal of Political Science 61(3):715-727.

URL: $h t t p: / / d x . d o i . o r g / 10.1111 /$ ajps.12290

Petrov, Slav, Dipanjan Das and Ryan McDonald. 2011. "A universal part-of-speech tagset." arXiv preprint arXiv:1104.2086 .

Porter, Martin F. 1980. "An algorithm for suffix stripping." Program 14(3):130-137.

Quinn, Kevin M, Burt L Monroe, Michael Colaresi, Michael H Crespin and Dragomir R Radev. 2010. "How to analyze political attention with minimal assumptions and costs." American Journal of Political Science 54(1):209-228.

Ratnaparkhi, Adwait. 1996. A maximum entropy model for part-of-speech tagging. In Proceedings of the Conference on Empirical Methods in Natural Language Processing-Volume 1. pp. 133-142.

Reagan, Ronald. 1984. "Remarks Accepting the Presidential Nomination.". Delivered on August 23 at the Republican National Convention in Dallas, Texas.

URL: https://www.reaganlibrary.gov/sites/default/files/archives/speeches/1984/82384f.htm

Roberts, Margaret E, Brandon M Stewart, Dustin Tingley, Edoardo M Airoldi et al. 2013. The structural topic model and applied social science. In Advances in Neural Information Processing Systems Workshop on Topic Models: Computation, Application, and Evaluation.

Robinson, Michael D, Deirdre M Cassidy, Ryan L Boyd and Adam K Fetterman. 2015. "The politics of time: Conservatives differentially reference the past and liberals differentially reference the future." Journal of Applied Social Psychology 45(7):391-399.

Romzek, Barbara S. 2000. "Accountability of congressional staff." Journal of Public Administration Research and Theory 10(2):413-446.

Romzek, Barbara S and Jennifer A Utter. 1997. "Congressional Legislative Staff: Political Professionals or Clerks?" American Journal of Political Science 41(4):1251-1279.

URL: $h t t p: / / w w w . j s t o r . o r g / s t a b l e / 2960489$

Russell, Bryan C, William T Freeman, Alexei A Efros, Josef Sivic and Andrew Zisserman. 2006. Using multiple segmentations to discover objects and their extent in image collections. In Proceedings of the 2006 IEEE Computer Society Conference on Computer Vision and Pattern Recognition. Vol. 2 IEEE pp. 1605-1614.

Schonhardt-Bailey, Cheryl. 2008. "The congressional debate on partial-birth abortion: Constitutional gravitas and moral passion." British Journal of Political Science 38(03):383-410.

Slapin, Jonathan B and Sven-Oliver Proksch. 2008. "A scaling model for estimating time-series party positions from texts." American Journal of Political Science 52(3):705-722.

Slatcher, Richard B, Cindy K Chung, James W Pennebaker and Lori D Stone. 2007. "Winning words: Individual differences in linguistic style among US presidential and vice presidential candidates." Journal of Research in Personality 41(1):63-75. 
Tausczik, Yla R and James W Pennebaker. 2010. "The psychological meaning of words: LIWC and computerized text analysis methods." Journal of language and social psychology 29(1):24-54.

Teh, Yee Whye, Michael I Jordan, Matthew J Beal and David M Blei. 2006. "Hierarchical Dirichlet Processes." Journal of the American Statistical Association 101(476):1566-1581.

Toutanova, Kristina, Dan Klein, Christopher D Manning and Yoram Singer. 2003. Feature-rich part-ofspeech tagging with a cyclic dependency network. In Proceedings of the 2003 Conference of the North American Chapter of the Association for Computational Linguistics on Human Language TechnologyVolume 1. Association for Computational Linguistics pp. 173-180.

Tversky, Amos and Daniel Kahneman. 1986. "Rational choice and the framing of decisions." Journal of business pp. S251-S278.

Udall, Sen. Tom. 2016. "Udall, Heinrich Introduce Organ Mountains-Desert Peaks Conservation Act." Press Release. Accessed November 28, 2017.

URL: https://www.tomudall.senate.gov/

Walgrave, Stefaan, Julie Sevenans, Kirsten Van Camp and Peter Loewen. 2017. "What Draws Politicians' Attention? An Experimental Study of Issue Framing and its Effect on Individual Political Elites." Political Behavior.

URL: https://doi.org/10.1007/s11109-017-9413-9

Wallach, Hanna M, David M Mimno and Andrew McCallum. 2009. Rethinking LDA: Why priors matter. In Advances in neural information processing systems. pp. 1973-1981.

Wang, Chong, John Paisley and David Blei. 2011. Online Variational Inference for the Hierarchical Dirichlet Process. In Proceedings of the Fourteenth International Conference on Artificial Intelligence and Statistics. Vol. 15 PMLR pp. $752-760$.

Wilson, Walter Clark and Roberto Felix Carlos. 2014. "Do Women Representatives Regender Legislative Bureaucracy? Assessing the Effect of Representative Sex on Women's Presence among US Congressional Staff." The Journal of Legislative Studies 20(2):216-235.

Yarkoni, Tal. 2010. "Personality in 100,000 words: A large-scale analysis of personality and word use among bloggers." Journal of Research in Personality 44(3):363-373. 
A Presidential Campaign Slogans 
Table 11: Presidential Campaign Slogans (1976-2016)

\begin{tabular}{lllll}
\hline Year & Dem Candidate & Democratic Slogan(s) & Rep Candidate & Republican Slogan(s) \\
\hline 1976 & Carter & Not Just Peanuts; A Leader, For a Change & Ford & He's Making Us Proud Again \\
1980 & Carter & A Tested and Trustworthy Team & Reagan & Let's Make America Great Again \\
1984 & Mondale & For New Leadership & Reagan & It's Morning Again in America \\
1988 & Dukakis & We're on Your Side & H.W. Bush & Read my lips: No new taxes \\
1992 & Bill Clinton & For People, for a Change; It's the economy stupid & H.W. Bush & Stand By the President \\
1996 & Bill Clinton & Building a Bridge to the 21st Century & Dole & The Better Man for America \\
2000 & Gore & Leadership for the New Millenium; Prosperity and Progress & W. Bush & Compassionate Conservatism; Reformer with Results \\
2004 & Kerry & A Stronger America; Let America be America Again & W. Bush & A Safer World and More Hopeful America \\
2008 & Obama & Change; Change We Can Believe In & McCain & Country First \\
2012 & Obama & Forward & Romney & Believe in America; America's Comeback Team \\
2016 & Hillary Clinton & Hillary for America; Forward Together & Trump & Make America Great Again \\
\hline
\end{tabular}




\section{B "Cyclic Dependency Network" Tagger Details}

This appendix provides a formal overview of the "Cyclic Dependency Network" tagger introduced by Toutanova et al. (2003). First, I present an overview of the feature set used. I then provide a generalization of the model from Toutanova et al. $(2003,174)$ in Equation 1. Third, the regularized objective function from (Toutanova et al., 2003, 178) is given by Equation 2. Finally, Equation 3 shows the chained local probabilities scoring function from (Toutanova et al., 2003, 175).

\section{B.1 Feature Set}

Table 12: Final Tagger Features - Toutanova et al. (2003)

\begin{tabular}{rll}
\hline Feature Type & Short Hand & Example $^{a, b}$ \\
\hline Individual Tags & $L+R$ & $L=t_{-1}$ \\
Tag-Tag Interactions & $L L_{2}+R R_{2}+L R$ & $L L_{2}=t_{-1} * t_{-2}$ \\
Individual Words & $w_{L}+w_{0}+w_{R}$ & $w_{L}=w_{-1}$ \\
Word-Word Interactions & $w_{0} w_{-1}+w_{0} w_{+1}$ & $w_{0} w_{-1}=w_{0} * w_{-1}$ \\
Tag-Word Interactions & $w_{0} L+w_{0} R$ & $w_{0} L=w_{0} * t_{-1}$ \\
\hline Character Level ${ }^{c}$ & E.g., char chc $_{\text {inc }}=1$ if 'Inc.' is within 3 words of a capitalized word \\
\hline
\end{tabular}

${ }^{a} t$ is used for tag features and $w$ is used for words.

${ }^{b}$ Toutanova et al. (2003) denote these features using bracket notation $t_{0}$ : e.g., $\left\langle t_{0}, t_{-1}, t_{-2}\right\rangle$ for the $L L_{2}$ feature. The leading current tag item $\left(t_{0}\right)$ represents that each feature has a different weight (coefficient in MNL regression) for each possible outcome.

c Also referred to as "unknown word features"; see Toutanova et al. $(2003,178)$ and Ratnaparkhi (1996) for details.

\section{B.2 Generalized Model}

Let $t_{0}$ be one of the $C$ possible tags for the center word in a given sequence. Further, let $t_{0}^{\prime}$ represent the alternative tags, where $t_{0}^{\prime}=[1, \ldots, C-1]$. Finally, define $\boldsymbol{x}$ as a $K$ length vector of features (see Table 12 for the features used by Toutanova et al.), where $x_{j}$ is the $j^{\text {th }}$ feature, $j=[1, \ldots, K]$. The general form of the model is then given by Equation 1:

$$
P_{\boldsymbol{\lambda}}\left(t_{0} \mid \boldsymbol{x}\right)=\frac{\exp \left(\sum_{j=1}^{K} \lambda_{\left\langle t_{0}, x_{j}\right\rangle}\right)}{\sum_{t_{0}^{\prime}=1}^{C-1} \exp \left(\sum_{j=1}^{K} \lambda_{\left\langle t_{0}^{\prime}, x_{j}\right\rangle}\right)}
$$

\section{B.3 Regularized Objective}

Let $F(\cdot)$ be the objective function for the model given described above. Then let $\boldsymbol{\lambda}$ be the $K$ length vector of weights assigned to features $\boldsymbol{x}$. Define $\sigma^{2}$ as regularization hyper-parameter - set to 0.5 by Toutanova et al. (2003, 178). The regularized objective function is then given by Equation 2: 


$$
F(\boldsymbol{\lambda})=\sum_{i} \log \left(P_{\boldsymbol{\lambda}}\left(t_{i} \mid \boldsymbol{x}\right)\right)+\sum_{j=1}^{K} \frac{\lambda_{j}^{2}}{2 \sigma^{2}}
$$

\section{B.4 Scoring Function}

Let $P a\left(\right.$ nodes $\left._{i}\right)$ be the nodes relevant to node $_{i}$ via the feature vector $\boldsymbol{x}$ (Toutanova et al., 2003, 175). The score is then a function of the "local probabilities from a dependency network" (Toutanova et al. 2003, 175), shown in Equation 3:

$$
\operatorname{score}(\text { nodes })=\prod_{i} P\left(\text { node }_{i} \mid P a\left(\text { nodes }_{i}\right)\right)
$$




\section{Topic Modeling Details}

This section provides additional details about the process of sorting press releases into topics. I sort documents into topics using the "Expressed Agenda" model (Grimmer 2010, 2013b). This approach differs significantly from the typical topic models: Latent Dirichlet Allocation (LDA) and its extensions (e.g., Blei and Lafferty 2006; Blei, Ng and Jordan 2003), and Non-negative Matrix Factorization (NMF; Paatero and Tapper 1994). ${ }^{42}$ Most importantly, LDA and NMF are mixed membership, while the "Expressed Agenda" model (Grimmer 2010) is single membership. This means that LDA and NMF are built on the assumption that a given document is generated as a mixture of topics (e.g., $20 \%$ healthcare, $50 \%$ trade, and $30 \%$ banking). Alternatively, single membership models assume is a particular document is generated by drawing a single topic (Grimmer 2010; Quinn et al. 2010).

This is an important distinction to draw between the methods especially in the context of press releases. Unlike a variety of other document types (e.g., news transcripts or academic articles), press releases are almost exclusively focused on a particular topic Grimmer $(2010,2013 b)$. Thus, a model that assumes documents are generated based on a mixture of topics seems ill-suited to the task. ${ }^{43}$

\section{C.1 Preparing the text}

Before the topic model can be fit, the text needs to first be processed: I generally follow the steps put forth by Grimmer (2010). Note that the tokenized, but un-tagged text data is used for this section. First, the text is lowercased and then stemmed using the Porter stemmer (Porter 1980). ${ }^{44}$ Stems appearing in the tails of the frequency distribution are unlikely to provide the model with any information and thus are removed. Specifically, stems appearing in fewer than $0.5 \%$ of documents, more than " $90 \%$ of any individual senator's press releases," (Grimmer 2010, pg. 7-8), or more than $90 \%$ of all documents are removed. I do not independently remove stop words (e.g., 'the', 'a', 'it') because the vast majority of them are removed by the upper bounds on frequency, and those that do not satisfy the $90 \%$ cutoff rules may still be valuable. Numbers are also removed from the documents as they are likely to add noise to the model due to their prevalence across issues. Each processed document is then represented in the typical bag-of-words fashion, using only unigrams. Document vectors are normalized to unit length using the Euclidean norm (Grimmer 2010). Due to the computational complexity of fitting and evaluating the model, these pre-processing decisions are not evaluated against possible alternatives (Denny and Spirling 2018).

\section{C.2 Estimating $K$ Topics}

Like most unsupervised topic models, the "Expressed Agenda" model requires the analyst to define the number of topics, $K$, that exist in the corpus a priori. This is a difficult task to get correct. Existing procedures to select the best value for $K$ vary: from purely qualitative assessment of topic coherence and coverage across model fits (Quinn et al. 2010) to a mixed-methods approach that validates the qualitative assessment with a quantitative estimation using a non-parametric model for clustering (Grimmer 2010, 2013b). I follow previous works (e.g., Grimmer 2010; Quinn et al. 2010) and estimate the model over a range of values: $K=[30,31, \ldots, 60]{ }^{45,46}$ Each of the resulting models is then evaluated for quality of fit. I adopt the standard laid out by Quinn et al.: "We set a goal of identifying topical categories that correspond roughly

\footnotetext{
${ }^{42}$ Both LDA and NMF have also been used outside of text analysis for more general purpose clustering, especially in the field of computer vision: e.g., for LDA see Russell et al. (2006) and for NMF see Lee and Seung (1999).

${ }^{43}$ Though, it is possible to force the LDA model to concentrate few topics per document by shrinking the $\alpha_{k}$ parameter on topic $k$ 's weight in document $d \in[1, \ldots, M]$. Giving $\boldsymbol{\alpha}$ an asymmetric prior can also make the model more robust (Wallach, Mimno and McCallum 2009).

${ }^{44}$ Stemming removes (and often substitutes) word suffixes. This is a dimensionality reduction technique that allows word base variants to be collapsed. A pair of example stems is 'flying' and 'fly' to 'fli'.

${ }^{45} \mathrm{I}$ also use the priors discussed in Grimmer (2010). Specifically, for each model, I set $\kappa_{k}=100 \forall k \in K$ (Grimmer 2010, 11). Each $\kappa_{k}$ is an inverse dispersion parameter of the mean for the $k^{\text {th }}$ von Mises-Fisher (vMF) distribution - one for each topic. The vMF distribution is a unit hyper-sphere with a mean $\boldsymbol{\mu}$, which in this model describes a "prototype document for the $k^{\text {th }}$ topic" Grimmer 2010, 10. As $\kappa_{k}$ approaches 0, the vMF converges toward a uniform distribution on the hypersphere, but as $\kappa_{k}$ approaches $\infty, \boldsymbol{\mu}_{k}$ becomes a "spike" at $\boldsymbol{\mu}$ Grimmer 2010, 10.

${ }^{46} \mathrm{I}$ use a less stringent cutoff for model convergence than Grimmer (2010). While he required the maximum change in $\boldsymbol{\alpha}$ (the senator-specific allocation parameter) to be less than 1e-05, I use a tolerance of 1e-04.
} 
to the areas of governmental competence typically used to define distinct government departments/ministries or legislative committees, such as 'Education,' 'Health,' and 'Defense,'” (2010, pg. 216).

In practice, this means that for every model, with $K=[30,31, \ldots, 60]$, I examined the ten words stems most strongly related to each topic - as defined by mutual information - to determine whether the topic coverage was sufficient or not. In cases where the breadth of a topic was unclear, I read a random sample of five press releases that had a posterior probability of being from the topic greater than $99 \%$. This process led me to select a model with 45 topics as being the most appropriate, which is in line with Grimmer $(K=43$; 2010) and Quinn et al. $(K=42 ; 2010) .{ }^{47}$

As an external validation of this selection, I fit a hierarchical Dirichlet process (HDP) model, which estimates $K$ from the data, and evaluate the posterior over the number of topics (Teh et al. 2006; Wang, Paisley and Blei 2011). I also validate using a non-hierarchical variational Dirichlet process model (Blei and Jordan 2006; Pedregosa et al. 2011) and evaluate component weight distributions. Both of these models are fit with an upper-bound of 100 topics and suggest that a model with 45 topics is appropriate. ${ }^{48}$

\section{C.3 Fitting and Labeling}

After selecting and validating that 45 is an appropriate number of topics, I re-fit the model an additional 100 times, each with a unique random start (Grimmer 2010). To deal with the limited guarantee of local convergence, the "best run" is used for inference (Grimmer 2010). ${ }^{49}$ From the "best run" model, I label each topic using the ten word-stems most strongly associated with the topic - by mutual information - and reading a random sample of ten documents with a high probability of assignment to the topic (Grimmer 2010). These labels and other topic descriptives can be found in Table 5, below. Documents are assigned to the topic with the highest probability of generating the document. Like Quinn et al. (2010, 215), I find that this assignment procedure results in minimal information loss: over $99 \%$ of documents are assigned to a single topic with greater than $95 \%$ probability.

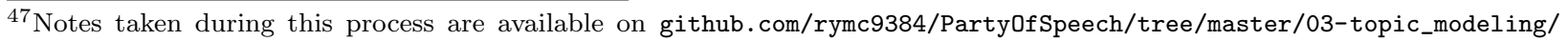
ExpAgenda/num_topics.

${ }^{48}$ It should be noted that these methods of validation are not perfect because they are multi-membership models. This means that documents can be composed of multiple topics, which constitutes a fundamental change in the assumed data generating process and affects model fit.

${ }^{49}$ The "best run" is determined by maximizing the evidence lower bound (ELBO). Effectively, this minimizes the KullbackLeibler divergence between the approximating and true posterior distributions (Jordan et al. 1999). For more information, consult the supplementary materials for Grimmer (2010).
} 


\section{Fightin' Words Details}

This section provides more details about the Fightin' Words model proposed in Monroe, Colaresi and Quinn (2008) - both in general and as implemented in Chapter ?? to assess partisan differences in style.

The final step in the analysis is to evaluate the differential use of grammatical features between the parties. While there are many methods that seem applicable to this task, most have been shown to have shortcomings in one or more situations. For instance, simple metrics like frequencies and proportions tend to reflect common words as being the most partisan (Monroe, Colaresi and Quinn 2008). More complex measures can produce equally poor results. Monroe et al. note that the oft used TF-IDF method (Manning and Schütze 1999, 541-44) provides rather nonsensical estimates when used for this purpose: "The most partisan words are the words spoken the most by one party, while spoken not once by the other," (2008, 381). Even with a large corpus and topic sub-corpora, the "most" partisan words using this measure likely appear fewer than 100 times (Monroe, Colaresi and Quinn 2008, 383).

As an alternative to this and other problematic methods, I use the "Fightin' Words" model (Monroe, Colaresi and Quinn 2008). This model allows for the selection and evaluation of differential word use by particular groups using smoothed log-odds ratios. Essentially, the model is very similar to fitting a logistic regression "of the binary choice, word $w$ versus any other word," on group indicator(s) (Monroe, Colaresi and Quinn 2008, 385), except that the "Fightin' Words" model also allows for the incorporation of priors that can induce estimate shrinkage. ${ }^{50}$ Since I am interested in partisan differences in grammar, the "regressor" is an indicator of political party (i.e., Republican or Democratic).

A few variables are needed for the model. Following Monroe, Colaresi and Quinn (2008), first let $\boldsymbol{w}=$ $1, \ldots, W$ be a $W$-length index of POS tag $n$-grams. In the confirmatory analyses, a "word" $w$ may be a sequence of one, two, or three adjacent tags; however, in exploratory analyses and robustness checks a "word" $w$ can be a sequence of lemma-tag pairs (e.g., 'be_VBN', 'will_MD help_VB', or 'i_PRP would_MD note_VB'). ${ }^{51,52}$ While using $n$-grams (instead of unigrams) violates the model's independence assumption, this is of little practical importance with a corpus as large as mine. Using unigrams as the unit of analysis where future tense sequences are substituted in the text as a single token - yields substantively equivalent results (typically differing only at the third or fourth decimal place).

Then let $\boldsymbol{y}$ be a $W$-length vector of counts associated with the POS $n$-grams indexed by $\boldsymbol{w}$. Further, $\boldsymbol{y}$ can be subset by topic $(k \in[1, \ldots, K])$ and party $(P=\{R, D\})$, so that $y_{k w}^{(D)}$ is a count of "word" $w$ in press releases from topic $k$ written by Democrats. Finally, let $n$ be the sum of counts from $\boldsymbol{y}$, and as $\boldsymbol{y}$ can be subset, so can $n$ : e.g., $n_{k}=\sum_{w=1}^{W} y_{w k}$.

As noted earlier, the "Fightin' Words" model is similar to fitting series of logistic regressions for each word $w \in \boldsymbol{w}$. For instance, ignoring topics, one of those regressions on the "word" $w$ would be set up with an $n$ length vector of binary outcomes. Call this vector $Y$. An instance of $Y$ is equal to one if the "word" $w$ is used and zero if any other word is used. Thus, $Y$ would be an $n$-length vector with $y_{w}$ ones and $n-y_{w}$ zeros. This would be regressed on an $n$-length vector, say $X$, indicating whether a given instance of $Y$ is associated with the Republican party. $X$ would contain $n^{(R)}$ ones - representing all the "words" used by Republicans - and $n^{(D)}$ zeros. The coefficient on $X$ then would be the log-odds-ratio of Republican to Democratic uses of "word" $w$ versus any other "word". This could also be calculated from a $2 \times 2$ contingency table.

The key difference between the logistic regression discussed above and the "Fightin' Words" model is that the latter uses a prior to regularize the estimated party differences. Monroe, Colaresi and Quinn (2008) define this prior to follow a Dirichlet distribution, parameterized by $\boldsymbol{\alpha} .{ }^{53}$ Here, $\boldsymbol{\alpha}$ is a $W$-length vector of positive values. For a given "word" $w$, the prior $\pi_{w} \sim \operatorname{Dirichlet}\left(\alpha_{w}\right)$ "affects the posterior exactly as if we had observed in the data an additional $a_{w}-1$ instances of word $w$," (Monroe, Colaresi and Quinn 2008, 384). Like other variables in the model, this can also be subset by topic and party. Finally, for notation purposes, let $\alpha_{0}=\sum_{w=1}^{W} \alpha_{w}$.

\footnotetext{
${ }^{50}$ More details about the model can be found in (Monroe, Colaresi and Quinn, 2008, 382-90).

${ }^{51}$ I use $n$-grams between one and three so that I can capture the "future" tense verbs without distorting the counts of their components. If the multi-token sequences are simply replaced in the texts before building the vocabulary, counts of their components will be distorted - though only by a small amount.

${ }^{52}$ In most robustness and exploratory analyses I use unigram counts. This is computationally easier and the difference in estimates caused by only using unigram token counts is only noticeable at the second decimal place.

${ }^{53}$ Monroe, Colaresi and Quinn $(2008,384)$ choose the Dirichlet as it is the conjugate for the multinomial and their model assumes $\boldsymbol{y}_{k} \sim \operatorname{Multinomial}\left(n_{k}, \boldsymbol{\pi}_{k}\right)$.
} 


\section{[need to clean up below]}

With this prior, the differences in word use by the parties (i.e., the "coefficient" on party indicator in the regression example) is estimated as:

$$
\hat{\delta}_{k w}^{(R-D)}=\log \left[\frac{\left(y_{k w}^{(R)}+\alpha_{k w}^{(R)}\right)}{n_{k}^{(R)}+\alpha_{k 0}^{(R)}-y_{k w}^{(R)}-\alpha_{k w}^{(R)}}\right]-\log \left[\frac{\left(y_{k w}^{(D)}+\alpha_{k w}^{(D)}\right)}{n_{k}^{(D)}+\alpha_{k 0}^{(D)}-y_{k w}^{(D)}-\alpha_{k w}^{(D)}}\right]
$$

Again, Equation 4 is simply the log-odds-ratio with some prior word counts incorporated. Monroe, Colaresi and Quinn note that as such, this is still a problematic measure because it fails to account for the higher variance associated with rarely used words, which leads to the most partisan words appearing relatively few times $(2008,385)$. Their solution then is to account for that variance, which can be approximated by:

$$
\sigma^{2}\left(\hat{\delta}_{k w}^{(R-D)}\right) \approx \frac{1}{\left(y_{k w}^{(R)}+\alpha_{k w}^{(R)}\right)}+\frac{1}{\left(y_{k w}^{(D)}+\alpha_{k w}^{(D)}\right)}
$$

This estimated variance of the difference in use of word $w$ by the parties enables us to standardize the measure, which is just the "Fightin' Words" model does:

$$
\hat{\zeta}_{k w}^{(R-D)}=\hat{\delta}_{k w}^{(R-D)} / \sqrt{\sigma^{2}\left(\hat{\delta}_{k w}^{(R-D)}\right)},
$$

where $\hat{\zeta}_{k w}^{(R-D)}$ is the statistic of interest for this model of differential word use. It is similar to the $z$ score on the party indicator coefficient in the regression example. Positive values of $\zeta_{w}^{(R-D)}$ indicate that "word" $w$ is associated with Republican press releases, while negative values indicate an association with Democratic releases.

\section{D.1 Priors}

For the inter-topic analyses I cannot generate a legitimate empirical prior based on data completely external to that which is used in the analysis without splitting the press releases. As such I set $\boldsymbol{\alpha}=\mathbf{0 . 0 1} .{ }^{54}$ In the intra-topic analyses, the prior is informed by "word" frequencies in other topics. For every document authored by a party $p$ in topic $k$, the prior adds an average (bipartisan) document based on word counts from the other topics. Let $d_{k}$ be the number of documents in topic $k$. Further, let $\neg k$ index topics other than $k$ (i.e, $\neg k=i \forall i \neq k \in[1, \ldots, K]$ ). Then the prior for a party $p$ in topic $k$ (i.e., $\boldsymbol{\alpha}_{k}^{(p)}$ ) is calculated in two steps. First, the total number of "words" to imply for party $p$ is calculated. This is the average number of tokens in a document (across the corpus), times the number of documents authored by party $p$ in topic $k$ : $\alpha_{k 0}^{(p)}=\frac{n}{d} \times d_{k}^{(p)}$. Then, this is used to scale the frequency of "words" from other topics (i.e., $\left.\boldsymbol{y}_{\neg k}\right)$. It is not uncommon for rare words to be used only by one party, which causes $\log (0)$ to appear in the model. This is corrected by simply adding a small constant, $c .{ }^{55}$ Thus, the prior for a party $p$ in topic $k$ is described by Equation 7:

$$
\boldsymbol{\alpha}_{k}^{(p)}=\boldsymbol{y}_{\neg k} \times \frac{\alpha_{k 0}^{(p)}}{n_{\neg k}}+c
$$

Under this specification, differences between the parties must be especially stark in order for those differences to be observed.

\footnotetext{
${ }^{54}$ Although unintuitive (i.e., observing $0.01-1$ instances of word $w$ ), this is a proper prior. With sufficiently large corpora, like the one being used here, the "Fightin' Words" model is invariant across a large range of priors.

${ }^{55} \mathrm{I}$ set $c=0.01$, which is uninformative, but avoids the $\log$ error.
} 


\section{E Intra-topic Significance}

Table 13: Feature Significance Within and Across Topics (114 ${ }^{\text {th }}$ Congress)

\begin{tabular}{|c|c|c|c|c|c|c|}
\hline Topic & $\begin{array}{l}\text { Past Tense } \\
\text { Verbs }\end{array}$ & $\begin{array}{l}\text { Future Tense } \\
\text { Verbs }\end{array}$ & $\begin{array}{l}\text { Singular } \\
\text { Pronouns }\end{array}$ & $\begin{array}{l}\text { Plural } \\
\text { Pronouns }\end{array}$ & $\begin{array}{l}\text { Singular } \\
\text { Nouns }\end{array}$ & $\begin{array}{l}\text { Plural } \\
\text { Nouns }\end{array}$ \\
\hline 0) All Topics & GOP & DEM & GOP & DEM & - & DEM \\
\hline 1) Localistic & - & - & GOP & - & - & DEM \\
\hline 2) Education 1 (funding) & - & - & GOP & - & - & DEM \\
\hline 3) Chemical Safety Bill & - & - & GOP & - & - & DEM \\
\hline 4) Guns & - & - & - & - & - & - \\
\hline 5) $E P A$ & GOP & - & GOP & DEM & GOP & DEM \\
\hline 6) Budget & GOP & - & GOP & - & - & DEM \\
\hline 7) Nat'l Issues (general) & GOP & - & GOP & - & - & DEM \\
\hline 8) Iran Deal & - & - & GOP & - & - & DEM \\
\hline 9) Immigration & GOP & - & GOP & - & - & DEM \\
\hline 10) $F C C$ & GOP & - & GOP & - & DEM & - \\
\hline 11) Airport Funding/Safety & - & - & GOP & GOP & - & DEM \\
\hline 12) $H U D / H H S$ & - & - & GOP & - & DEM & DEM \\
\hline 13) Health Care & GOP & - & GOP & - & - & DEM \\
\hline 14) $V A$ & GOP & - & GOP & - & - & DEM \\
\hline 15) Oil And Gas & - & - & GOP & - & - & DEM \\
\hline 16) Banking/Finance & - & - & GOP & - & - & - \\
\hline 17) Terrorism & - & - & GOP & - & DEM & - \\
\hline 18) Symbolic & GOP & - & GOP & - & - & DEM \\
\hline 19) Research & GOP & - & GOP & DEM & - & DEM \\
\hline 20) Sexual/Domestic Violence & GOP & - & GOP & DEM & - & DEM \\
\hline 21) Consumer Protection & GOP & - & GOP & - & - & DEM \\
\hline 22) EMS/Fire Dept. Funding & - & - & GOP & - & - & DEM \\
\hline 23) Small Business & - & - & GOP & - & - & DEM \\
\hline 24) Trade & - & - & GOP & - & - & DEM \\
\hline 25) Jobs & - & - & GOP & - & - & DEM \\
\hline 26) Education 2 (K-12) & - & - & GOP & - & - & DEM \\
\hline 27) Legislation & GOP & - & GOP & - & - & DEM \\
\hline 28) Defense & - & - & GOP & - & GOP & DEM \\
\hline 29) Judicial & GOP & - & GOP & - & - & DEM \\
\hline 30) President & GOP & - & GOP & - & - & DEM \\
\hline 31) Nat'l Parks/Lands & GOP & DEM & GOP & DEM & - & DEM \\
\hline 32) Infrastructure & GOP & DEM & GOP & DEM & - & DEM \\
\hline 33) Drugs & GOP & - & GOP & DEM & GOP & DEM \\
\hline 34) Agency Oversight & - & - & GOP & DEM & - & DEM \\
\hline 35) Pork Spending & - & DEM & GOP & - & GOP & DEM \\
\hline 36) Rural Services & - & - & GOP & - & GOP & DEM \\
\hline 37) Law Enforcement & - & - & GOP & - & GOP & DEM \\
\hline 38) Investigations & GOP & - & GOP & DEM & - & DEM \\
\hline 39) Student Loans & - & - & - & DEM & GOP & DEM \\
\hline 40) Homeland Security & GOP & - & GOP & - & - & DEM \\
\hline 41) Children & - & - & - & - & - & DEM \\
\hline 42) Taxes & - & - & GOP & - & - & DEM \\
\hline 43) Energy & - & - & GOP & - & - & DEM \\
\hline 44) Zika & - & - & GOP & - & - & DEM \\
\hline 45) Climate Change & - & - & GOP & DEM & GOP & DEM \\
\hline $\begin{array}{l}n(\%) \text { Topics w/ Sig. Relationship } \\
\text { in Hypothesized Direction }\end{array}$ & $\begin{array}{c}19 \\
(42 \%)\end{array}$ & $\begin{array}{c}3 \\
(7 \%)\end{array}$ & $\begin{array}{c}42 \\
(93 \%)\end{array}$ & $\begin{array}{c}10 \\
(22 \%)\end{array}$ & $\begin{array}{c}8 \\
(18 \%)\end{array}$ & $\begin{array}{c}41 \\
(91 \%)\end{array}$ \\
\hline
\end{tabular}




\section{F $\quad 113^{\text {th }}$ Congress}

\section{F.1 Topics}

Press releases from the $113^{\text {th }}$ Congress were sorted into topics according to the same process as releases from the $114^{\text {th }}$ Congress. That a model with 45 topics was chosen for both is coincidental. 
Table 14: Topic Labels and Descriptives (113 ${ }^{\text {th }}$ Congress)

\begin{tabular}{|c|c|c|c|}
\hline Topics & Stems & $\%^{a}$ & Notes \\
\hline 1) Social Welfare & unemploy, benefit, insur, million, extend & $0.87 / 1.62$ & incl. benefits programs, pro-PPACA statements \\
\hline 2) Flood Insurance/Nat'l Parks & land, flood, park, insur, forest & $2.11 / 2.40$ & incl. "protecting homeowners" or jobs \\
\hline 3) Banking/Finance & bank, financ, institut, taxpay, system & $1.28 / 1.91$ & incl. bailout, Volker rule, court noms mixed in b/c DOJ and calls for criminal suits \\
\hline 4) Small Business & busi, small, help, economi, econom & $1.86 / 0.85$ & incl. economic development \\
\hline 5) Air Travel & airport, faa, fund, aviat, air & $1.46 / 1.36$ & incl. grants and "Airport Improvement Program" \\
\hline 6) Trade & trade, iran, nuclear, import, steel & $1.82 / 2.08$ & very broad coverage based on sampled docs \\
\hline 7) Infrastructure & project, fund, develop, transport, infrastructur & $2.80 / 1.72$ & incl. environmental issues related to Keystone XL and Superfund sites \\
\hline 8) Health Care 1 & health, care, mental, act, provid & $2.27 / 0.80$ & incl. mental health and Ebola \\
\hline 9) Localistic & counti, meet, street, staff, town & $1.71 / 1.77$ & incl. local grants, programs supporting local jobs, and constituency services/meetings \\
\hline 10) Energy & oil, pipelin, project, approv, permit & $1.31 / 2.08$ & incl. oil pipelines (Keystone XL, Midla), energy security, and environment \\
\hline 11) Children & children, famili, child, program, support & $1.61 / 1.02$ & incl. SNAP, pre-K, school repair, health care \\
\hline 12) Drugs & drug, prescript, abus, law, health & $1.08 / 0.87$ & incl. pricing, addiction, consumer protection \\
\hline 13) Letters & letter, postal, plan, secretari, provid & $3.05 / 3.90$ & incl. mostly letters to the President or other executive officials \\
\hline 14) Social/Homeland Security & secur, social, homeland, need, also & $2.38 / 1.11$ & incl. retirment benefits (e.g., pensions) and the sequester \\
\hline 15) Jobs 1 & employ, worker, wage, act, pay & $2.04 / 2.01$ & incl. government shutdown, employment regs \\
\hline 16) Education & school, student, educ, high, program & $2.04 / 1.26$ & incl. primary and secondary ed \\
\hline 17) Program/Grant Funding & fund, program, million, provid, support & $3.19 / 0.80$ & incl. primarily large grants \\
\hline 18) Investigations & report, gener, investig, administr, agenc & $2.92 / 5.98$ & incl. honorific statements too \\
\hline 19) Budget & budget, debt, cut, need, tax & $3.29 / 4.12$ & incl. debt ceiling, balance budget \\
\hline 20) Climate Change & climat, chang, power, rule, propo & $2.07 / 3.36$ & incl. regulations, energy productio \\
\hline 21) Symbolic & one, famili, countri, time, help & $5.89 / 11.33$ & incl. remembrance and honorific \\
\hline 22) Water & water, lake, act, river, protect & $2.00 / 1.16$ & incl. western droughts, rights and protections, int'l support for clean water \\
\hline 23) Econ Development & program, educ, help, train, provid & $2.61 / 1.82$ & incl. infrastructure, job training, student loans also prevalent \\
\hline 24) Veterans Affairs & veteran, care, health, provid, time & $4.77 / 1.14$ & incl. health care, delays in care and benefits, V-Day \\
\hline 25) Consumer Protection & consum, protect, internet, commiss, rule & $1.66 / 2.06$ & incl. CFPB, NSA, govt transparency/FOIAs \\
\hline 26) Legislative & amend, vote, right, act, law & $2.06 / 2.37$ & incl. votes, bill and constitutional amendments, lots of symbolic statements and bills \\
\hline 27) Judicial 1 & court, judg, law, district, nomin & $2.11 / 2.35$ & incl. nominations, responses to decisions, and cabinet noms \\
\hline 28) Immigration & immigr, border, secur, law, system & $2.88 / 3.22$ & incl. children, DACA, reform \\
\hline 29) Agriculture & farm, program, agricultur, farmer, crop & $2.26 / 1.11$ & incl. research, FDA, school food \\
\hline 30) Judicial 2 & nomin, confirm, vote, court, judg & $1.97 / 1.84$ & incl. nominations and nuclear option \\
\hline 31) LIHEAP & assist, famili, fund, home, program & $0.72 / 1.65$ & incl. low income home energy assistance program, other energy like LNG and oil \\
\hline 32) Jobs 2 & manufactur, innov, industri, develop, technolog & $1.30 / 1.31$ & incl. creation, attracting tech jobs, improve economic opportunity \\
\hline 33) Health Care 2 & care, health, provid, medicar, child & $1.46 / 1.02$ & incl. children, Medicare, rural care \\
\hline 34) Foreign Affairs & syria, ukrain, militari, russia, support & $2.76 / 3.92$ & incl. sanctions, New START, Boko Haram \\
\hline 35) FDA & fda, tobacco, food, market, health & $0.75 / 2.78$ & incl. tobacco marketing regs, Avastin drug \\
\hline 36) Student Loans & student, loan, rate, educ, debt & $1.84 / 1.16$ & incl. debt, general higher ed \\
\hline 37) Human Rights & right, human, freedom, israel, intern & $2.50 / 3.90$ & incl. Georgian arrests, Israel, immigration \\
\hline 38) Disasters & disast, fund, assist, damag, sandi & $1.98 / 2.18$ & incl. Sandy, CO fires, western drought \\
\hline 39) Violence & violenc, law, gun, victim, act & $2.33 / 1.89$ & incl. guns, sexual/domestic, trafficking \\
\hline 40) Taxes & tax, busi, credit, act, compani & $2.06 / 1.09$ & incl. internet sales, individual mandate \\
\hline 41) Grants & fire, firefight, grant, program, fund & $2.38 / 0.85$ & incl. fire depts, first responders, \\
\hline 42) Defense & militari, forc, air, defen, sexual & $3.59 / 1.96$ & incl. homeland, funding, sexual assault \\
\hline 43) Trains & safeti, rail, transport, train, car & $1.34 / 2.01$ & incl. new lines, derailments \\
\hline 44) Healthcare 3 & health, care, law, obamacar, insur & $2.75 / 3.03$ & incl. PPACA, exchange website, mandate \\
\hline 45) Agencies & act, agenc, help, requir, support & $2.86 / 1.86$ & incl. oversight, regional assistance, symbolic leg \\
\hline
\end{tabular}

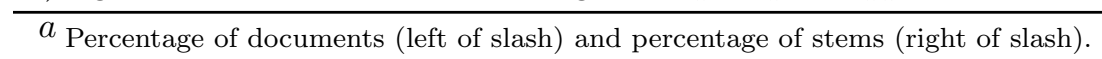




\section{G Future Tense 'Would' with Context}

Table 15: Most Partisan Future Tense 'Would' Phrases in Corpus

(Uninformative Dirichlet Prior)

\begin{tabular}{lrr|lcr}
\hline \multicolumn{4}{c}{ Republican } & \multicolumn{4}{c}{ Democratic } \\
\hline Phrase & $\zeta_{w}^{(R-D)}$ & Total Freq. & Phrase & $\zeta_{w}^{(R-D)}$ & Total Freq. \\
\hline i would note & 6.02 & 65 & which would help & -6.50 & 205 \\
i would encourage & 5.43 & 74 & that would help & -6.26 & 518 \\
i would say & 5.11 & 92 & bill would help & -5.13 & 259 \\
congress would have & 4.98 & 55 & act would provide & -4.60 & 146 \\
that would prohibit & 4.72 & 149 & act would give & -4.50 & 75 \\
it would be & 4.52 & 745 & that would extend & -4.38 & 97 \\
that would stop & 4.25 & 36 & and would be & -3.93 & 142 \\
i would like & 4.18 & 663 & bill would establish & -3.91 & 86 \\
there would be & 4.11 & 147 & act would help & -3.71 & 155 \\
it would require & 4.08 & 97 & act would ensure & -3.68 & 100 \\
which would require & 3.85 & 233 & that would close & -3.60 & 45 \\
rule would have & 3.73 & 46 & that would restore & -3.47 & 58 \\
that would prevent & 3.71 & 66 & funding would allow & -3.46 & 45 \\
i would ask & 3.55 & 25 & bill would give & -3.40 & 81 \\
otherwise would have & 3.41 & 421 & bill would make & -3.33 & 41 \\
that would require & 3.33 & 22 & funding would help & -3.27 & 108 \\
president would be & 3.27 & 39 & that would give & -3.07 & 35 \\
it would do & 3.18 & 41 & act would expand & -3.02 & 61 \\
bill would direct & 3.15 & 19 & which would establish & -3.02 & 52 \\
that would mean & 3.12 &
\end{tabular}

Note: This table is an exploratory analysis of the word 'would' when used in a "future tense verb phrase". The phrases seen here are all contain the word 'would' (tagged as a modal verb; MD) followed by an adverb-base verb pair (RB VB) or a base verb (VB). 


\section{H Intra-Party Pronoun Use by Gender}

Table 16: Most Gendered Pronouns in Democratic Releases

\begin{tabular}{lrr|lrr}
\hline \multicolumn{3}{c}{ Females } & \multicolumn{3}{c}{ Males } \\
\hline Lemma & $\zeta_{w}^{(F-M)}$ & Total Freq. & Lemma & $\zeta_{w}^{(F-M)}$ & Total Freq. \\
\hline her $^{a}$ & 60.61 & 7,001 & he & -33.87 & 13,039 \\
she & 52.38 & 5,586 & his & -32.60 & 15,835 \\
her & 15.31 & 1,217 & its & -14.03 & 19,577 \\
they & 12.77 & 34,899 & it & -13.14 & 53,756 \\
them & 6.39 & 12,064 & we & -8.18 & 68,918 \\
their & 4.75 & 52,100 & your & -6.94 & 7,955 \\
herself & 3.69 & 66 & you & -6.18 & 16,985 \\
our & 3.59 & 70,218 & itself & -3.84 & 537 \\
my & 1.98 & 10,954 & ourselves & -3.21 & 351 \\
ours & 1.89 & 151 & themselves & -2.73 & 1,642 \\
i & 1.89 & 52,841 & himself & -2.36 & 232 \\
's & 1.44 & 85 & him & -1.84 & 2,379 \\
myself & 0.75 & 159 & us & -1.69 & 7,845 \\
\hline
\end{tabular}

Note: This table is an exploratory analysis of pronoun use by female and male Democrats. The results are based on the unigram model with across all topics with an uninformative Dirichlet prior. Five pronouns are not included in the table: 'me', 'one', 'ya', 'yourself', and 'theirs'. All of these are very weakly aligned with either male or female senators and only 'me' is used more than 100 times.

a 'Her' appears twice in this list because the possessive and personal forms of this word are analyzed independently. 
Table 17: Most Gendered Pronouns in Republican Releases

\begin{tabular}{|c|c|c|c|c|c|}
\hline \multicolumn{3}{|c|}{ Females } & \multicolumn{3}{|c|}{ Males } \\
\hline Lemma & $\zeta_{w}^{(F-M)}$ & Total Freq. & Lemma & $\zeta_{w}^{(F-M)}$ & Total Freq. \\
\hline $\operatorname{her}^{a}$ & 43.82 & 4,500 & it & -27.27 & 52,791 \\
\hline she & 35.58 & 3,874 & his & -26.60 & 17,513 \\
\hline our & 17.90 & 51,761 & he & -26.27 & 14,874 \\
\hline her & 6.46 & 775 & they & -9.11 & 25,517 \\
\hline $\mathrm{i}$ & 5.03 & 47,552 & its & -8.16 & 15,393 \\
\hline my & 4.48 & 10,814 & us & -6.24 & 7,117 \\
\hline your & 3.08 & 6,080 & we & -6.01 & 52,799 \\
\hline you & 2.67 & 16,487 & itself & -5.25 & 735 \\
\hline myself & 0.86 & 170 & himself & -5.24 & 412 \\
\hline their & 0.35 & 32,273 & him & -4.71 & 2,647 \\
\hline- & - & - & them & -4.39 & 9,013 \\
\hline- & - & - & themselves & -3.81 & 961 \\
\hline- & - & - & 's & -2.64 & 86 \\
\hline- & - & - & yourself & -1.74 & 76 \\
\hline- & - & - & herself & -1.70 & 65 \\
\hline - & - & - & one & -1.64 & 101 \\
\hline- & - & - & ourselves & -1.55 & 270 \\
\hline- & - & - & ours & -0.80 & 93 \\
\hline- & - & - & me & -0.76 & 3,306 \\
\hline
\end{tabular}

Note: This table is an exploratory analysis of pronoun use by female and male Republicans. The results are based on the unigram model with across all topics with an uninformative Dirichlet prior. Three pronouns are not included in the table: 'theirs', 'all', and 'ya'. 'Theirs' is used twelve times and the latter two are only used three times each. All are very weakly aligned with male Republicans.

$a$ 'Her' appears twice in this list because the possessive and personal forms of this word are analyzed independently.

\section{Changes in Odds by Topic}


Figure 4: Change in Past Tense Verb Odds by Topic (114 ${ }^{\text {th }}$ Congress)

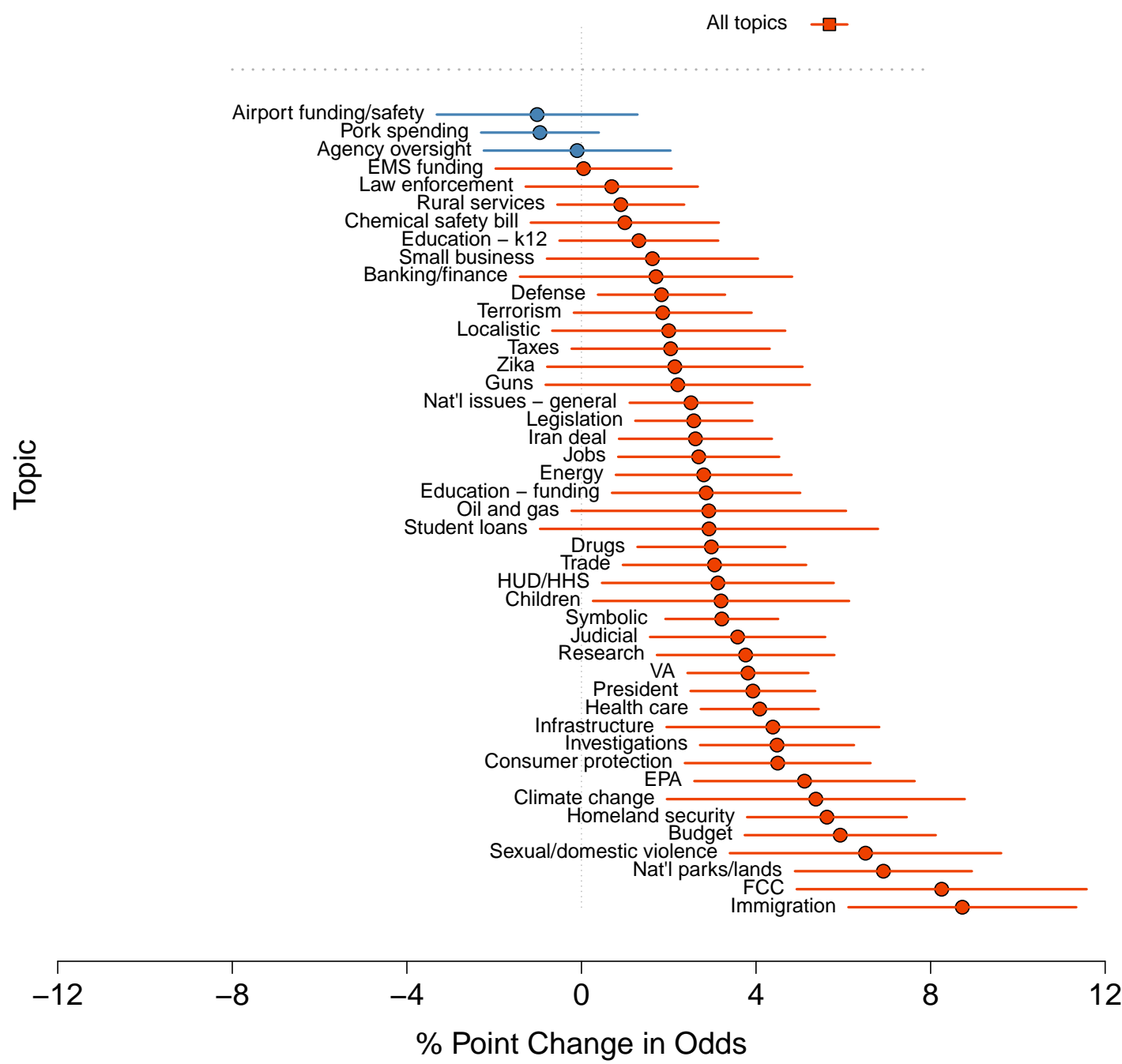

Note: The x-axis shows the percentage point increase(decrease) in odds of a token being a past tense verb, given that it appears in a Republican press release (vs a Democratic release). The y-axis separates those odds by topic, with the odds across all topics appearing at the top. Estimates are represented as points and error bars show $95 \%$ CIs. 
Figure 5: Change in Future Tense Verb Odds by Topic (114 ${ }^{\text {th }}$ Congress)

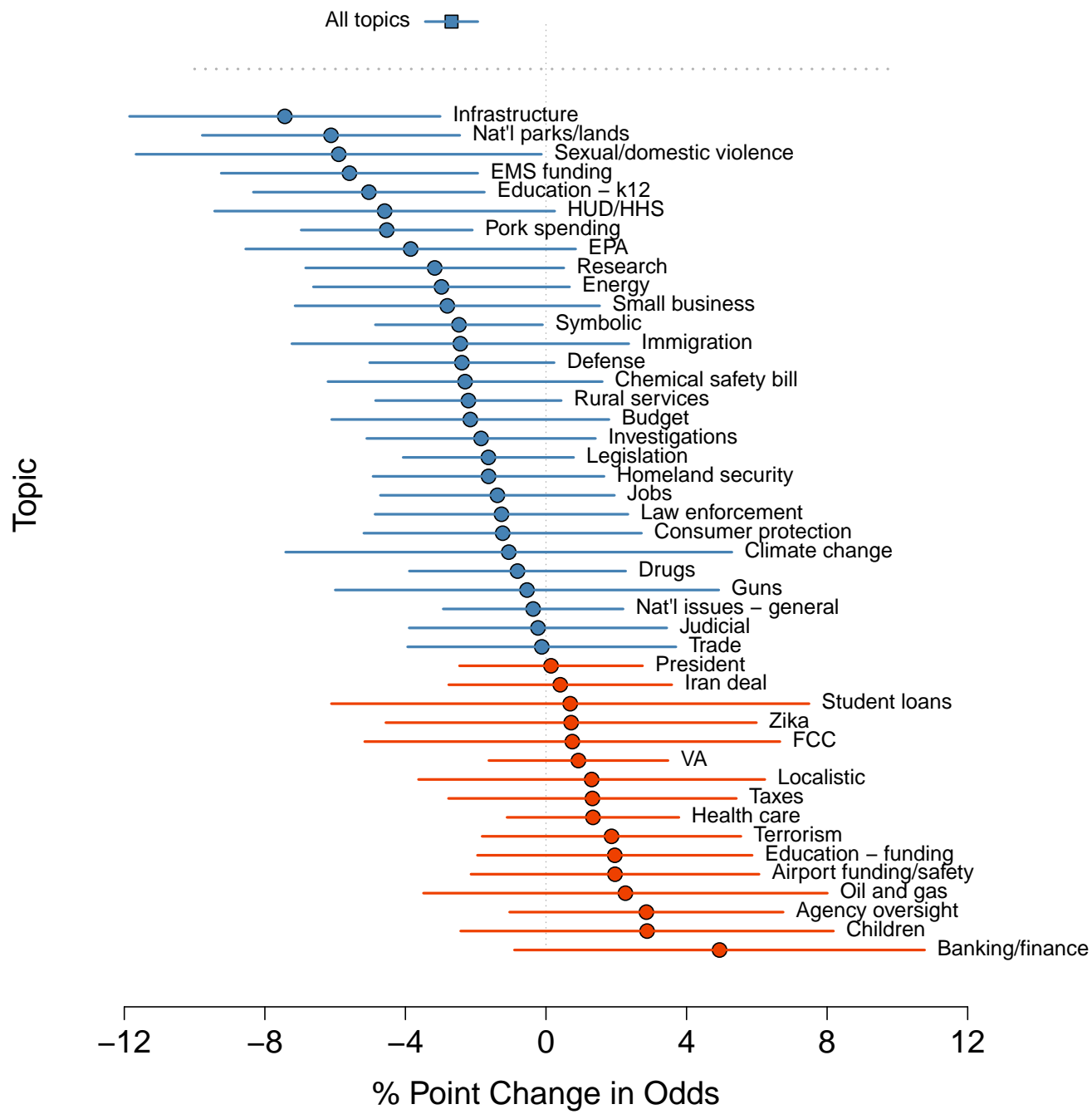

Note: The x-axis shows the percentage point increase(decrease) in odds of a token being a future tense verb, given that it appears in a Republican press release (vs a Democratic release). The y-axis separates those odds by topic, with the odds across all topics appearing at the top. Estimates are represented as points and error bars show $95 \%$ CIs. 
Figure 6: Change in Singular Pronoun Odds by Topic (114 ${ }^{\text {th }}$ Congress)

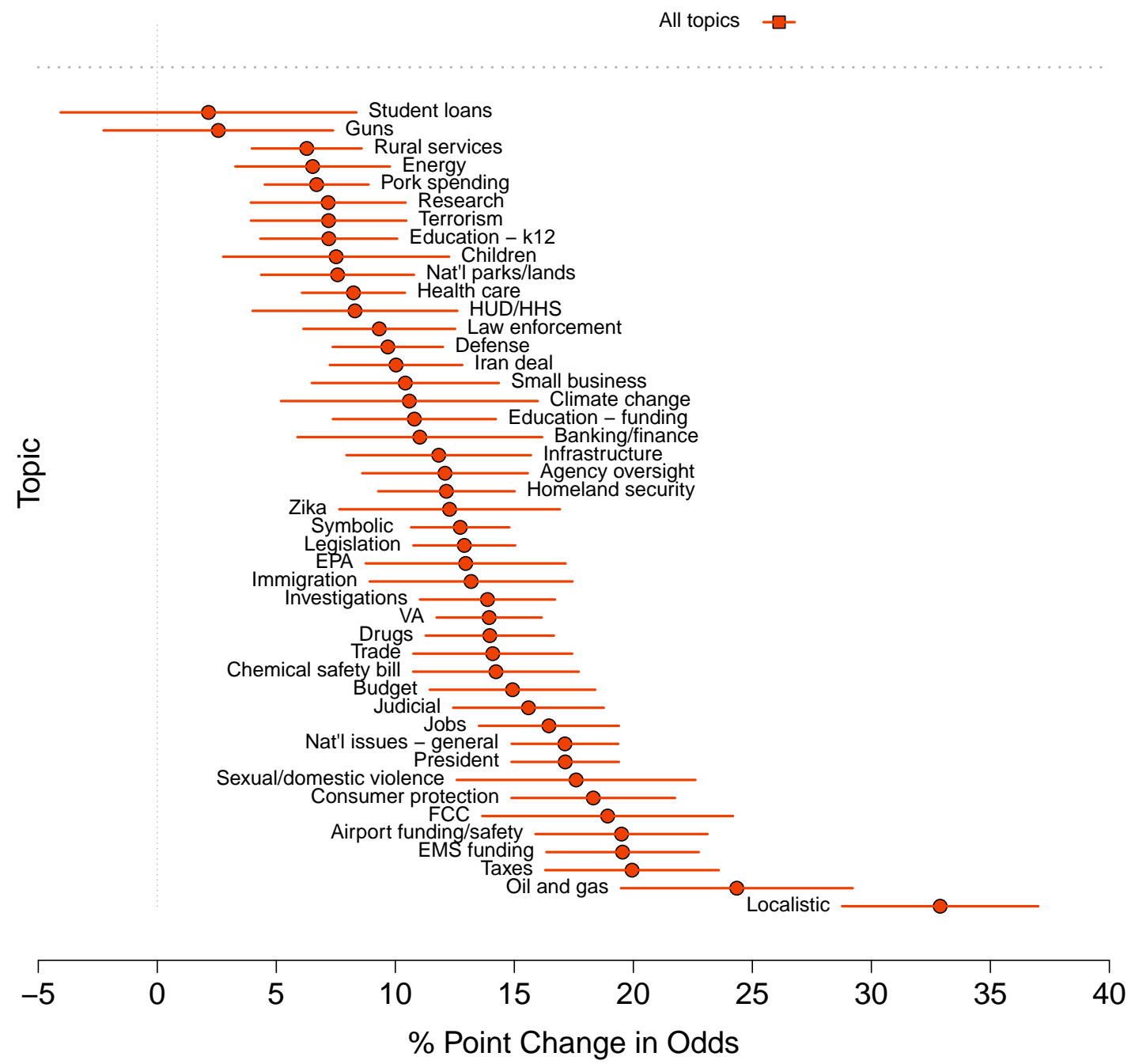

Note: The x-axis shows the percentage point increase(decrease) in odds of a token being a singular pronoun, given that it appears in a Republican press release (vs a Democratic release). The y-axis separates those odds by topic, with the odds across all topics appearing at the top. Estimates are represented as points and error bars show $95 \%$ CIs. 
Figure 7: Change in Plural Pronoun Odds by Topic (114 $4^{\text {th }}$ Congress)

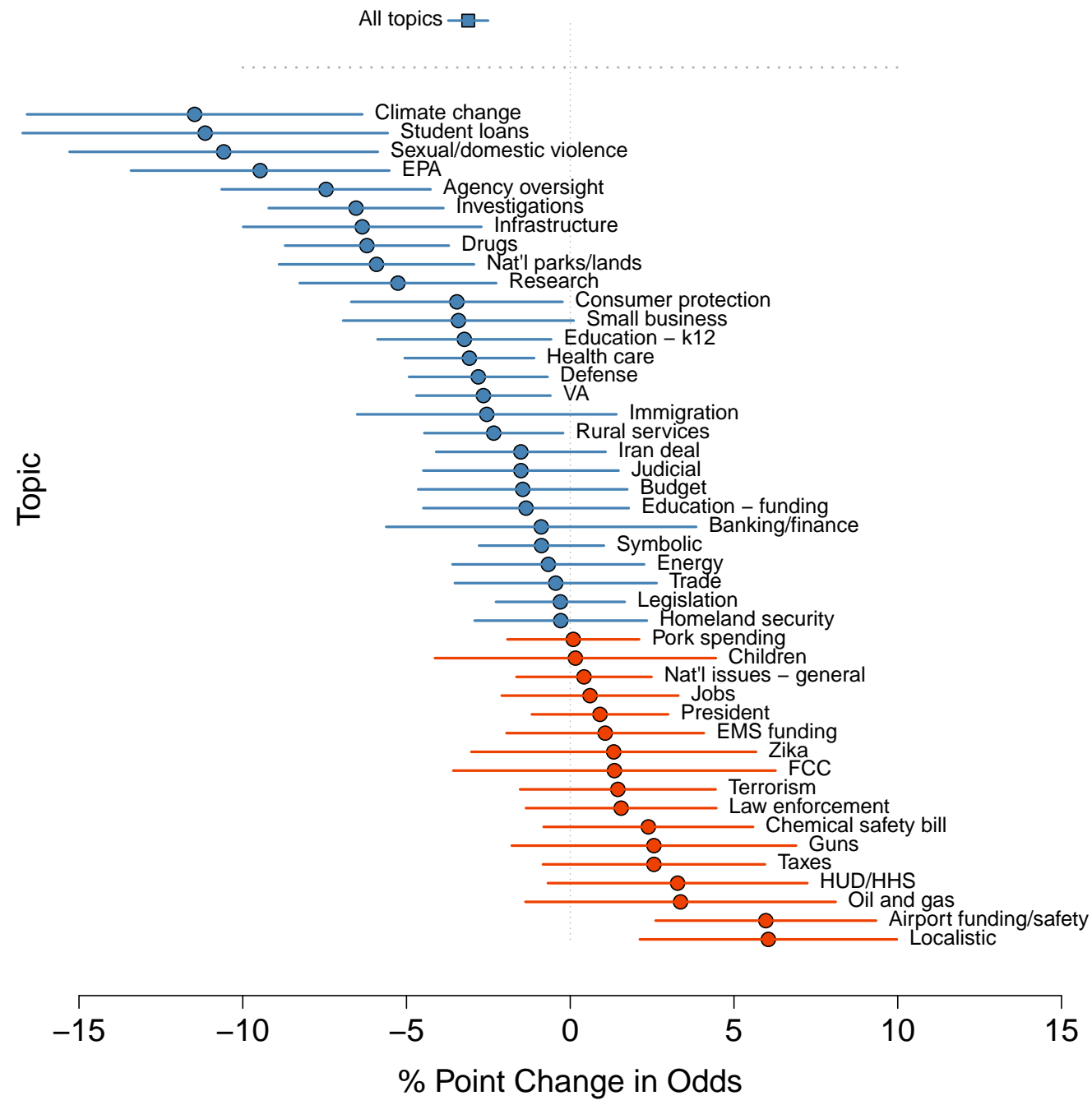

Note: The x-axis shows the percentage point increase(decrease) in odds of a token being a plural pronoun, given that it appears in a Republican press release (vs a Democratic release). The y-axis separates those odds by topic, with the odds across all topics appearing at the top. Estimates are represented as points and error bars show $95 \%$ CIs. 